1

2

3

4

5

6

7

8 . 17

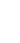
3

\title{
Including Sentinel-1 radar data to improve the disaggregation of MODIS land surface temperature data
}

\author{
Abdelhakim Amazirh ${ }^{\mathrm{a}, \mathrm{b},}$, Olivier Merlin ${ }^{\mathrm{b}}$, Salah Er-Raki ${ }^{\mathrm{a}}$.
}

${ }^{a}$ LP2M2E, Département de Physique Appliquée, Faculté des Sciences et Techniques, Université Cadi Ayyad, Marrakech, Morocco. Emails: abdelhakim.amazirh@ced.uca.ma \& s.erraki@uca.ma

${ }^{\mathrm{b}}$ CESBIO, Université de Toulouse, CNES/CNRS/IRD/UPS, Toulouse, France. Emails: olivier.merlin@cesbio.cnes.fr 15 16 18 1 (1) 4 (1) Ayyad University. Av. Abdelkarim Elkhattabi. B.P 549, 40000 Marrakech, Morocco Tel: (+212) (0) 524433404 / Mobile: (+212) (0) 632627075 / Fax: (+212) (0) 524433170 


\section{Abstract}

The use of land surface temperature (LST) for monitoring the consumption and water status of crops requires data at fine spatial and temporal resolutions. Unfortunately, the current spaceborne thermal sensors provide data at either high temporal (e.g. MODIS: Moderate Resolution Imaging Spectro-radiometer) or high spatial (e.g. Landsat) resolution separately. Disaggregating low spatial resolution (LR) LST data using ancillary data available at high spatio-temporal resolution could compensate for the lack of high spatial resolution (HR) LST observations. Existing LST downscaling approaches generally rely on the fractional green vegetation cover $\left(f_{\mathrm{gv}}\right)$ derived from HR reflectances but they do not take into account the soil water availability to explain the spatial variability in LST at HR. In this context, a new method is developed to disaggregate kilometric MODIS LST at $100 \mathrm{~m}$ resolution by including the Sentinel-1 (S-1) backscatter, which is indirectly linked to surface soil moisture, in addition to the Landsat-7 and Landsat-8 (L-7 \& L-8) reflectances. The approach is tested over two different sites -an $8 \mathrm{~km}$ by $8 \mathrm{~km}$ irrigated crop area named "R3" and a $12 \mathrm{~km}$ by $12 \mathrm{~km}$ rainfed area named "Sidi Rahal" in central Morocco (Marrakech)- on the seven dates when S1, and L-7 or L-8 acquisitions coincide with a one-day precision during the 2015-2016 growing season. The downscaling methods are applied to the $1 \mathrm{~km}$ resolution MODIS-Terra LST data, and their performance is assessed by comparing the $100 \mathrm{~m}$ disaggregated LST to Landsat LST in three cases: no disaggregation, disaggregation using Landsat $f_{g v}$ only, disaggregation using both Landsat $f_{g v}$ and $S-1$ backscatter. When including $f_{g v}$ only in the disaggregation procedure, the mean root mean square error in LST decreases from 4.20 to $3.60{ }^{\circ} \mathrm{C}$ and the mean correlation coefficient (R) increases from 0.45 to 0.69 compared to the non-disaggregated case within R3. The new methodology including the S-1 backscatter as input to the disaggregation is found to be systematically more accurate on the available dates with a disaggregation mean error decreasing to $3.35{ }^{\circ} \mathrm{C}$ and a mean $\mathrm{R}$ increasing to 0.75 .

Keywords: LST; disaggregation; soil moisture, Sentinel-1; MODIS/Terra; Landsat.

\section{Introduction}

Land surface temperature (LST) derived from thermal infrared remote sensing is an essential input variable for various environmental and hydro-meteorological applications. LST data are practically used for modeling the land surface processes and monitoring the functioning of agro-ecosystems (Anderson et al., 2008; Brunsell and Gillies, 2003; Karnieli et al., 2010; 
Kustas and Anderson, 2009; Zhang et al., 2008). Therefore, LST data have been used in a variety of applications such as, among others, climate studies (Hansen et al., 2010; Kustas and Anderson, 2009), the monitoring of crop water consumption (Amazirh et al., 2017; Bastiaanssen et al., 1998; Boulet et al., 2007; Er-Raki et al., 2018; Olivera-Guerra et al., 2018; Price, 1982), vegetation monitoring (Kogan, 2001; Williamson, 1988), soil moisture estimation (Amazirh et al., 2018; Merlin et al., 2010; Sandholt et al., 2002), and hydrological studies (Crow and Wood, 2003). However, there is a limitation in the existing satellite thermal sensors, since those with high revisit cycles (e.g, MODerate resolution Imaging Spectroradiometer 'MODIS') do not offer high spatial resolution (HR), and those offering HR (e.g, Landsat-8) generally have low temporal resolution (Agam et al., 2007b). In contrast, the visible and near infrared (VNIR) reflectance data are available at a resolution finer than that of most thermal sensors (Ha et al., 2013). To bridge the gap, the finer-resolution VNIR data have hence been extensively used as ancillary data to disaggregate low-resolution (LR) LST at HR.

Recently, various efforts have been devoted to disaggregate LST to a finer -typically $100 \mathrm{~m}$ resolution. Techniques are generally based on a relationship between LST and ancillary (vegetation cover indexes, emissivity and/or albedo) data, the obtained relationship being assumed to be scale invariant (and thus applied at both HR and LR). The statistical downscaling methods in particular, developed by Kustas et al. (2003) over a homogenous vegetated area, has been widely used. This method is based on a linear regression relationship between LST and NDVI (Normalized Difference Vegetation Index) calibrated at LR. The relation between LST and NDVI is also used in Bindhu et al. (2013), with the aim of developing a nonlinear method to estimate LST at HR. Agam et al. (2007a) used the fraction of green vegetation cover instead of NDVI. This method showed its capability and good performance over areas with relatively uniform soil and vegetation hydric status, where the temperature of bare soil is set to the average between the dry and wet soil over the studied area. Other studies reported that NDVI ( or $\mathrm{f}_{\text {gv }}$ ) shows some limitations and cannot explain all the variations in LST over agricultural areas (Agam et al., 2007b, 2007a; Inamdar and French, 2009; Merlin et al., 2010; Olivera-Guerra et al., 2017). Especially, Agam et al. (2007b) and Merlin et al. (2010) observed a shortcoming when using the LST-NDVI or LST- $f_{\text {gv }}$ relationship over areas with high moisture content, or with various photosynthetic activity vegetation types. Merlin et al. (2010) adapted this method to heterogeneous vegetation status, by adding the fraction of senescent vegetation cover to include the photosynthesis activity of 
vegetation, and to distinguish between areas of bare soil and dry vegetation cover. Dominguez et al. (2011) integrated the surface albedo to estimate HR LST by fitting the relationship between LST, NDVI and surface albedo. Following the same idea of adding other information that affect the spatial distribution of LST, Merlin et al. (2012) used the projection technique theoretically developed in Merlin et al. (2005) that aims to strengthen the correlation between two variables (LST and NDVI) by representing the dependence of these variables on other additional variables, based on a radiative transfer equation. Moreover, other studies were further presented involving additional factors that reflect the vegetation type (Merlin et al., 2010; Sandholt et al., 2009; Zhan et al., 2011). Sandholt et al. (2002) summarized the variables that affect LST variability, and they mentioned that, surface soil moisture (SM) mainly controls evapotranspiration and thermal properties of the surface, which affect LST. Therefore, optimal LST disaggregation approaches should include the variability of SM in addition to NDVI ( or $\mathrm{f}_{\mathrm{gv}}$ ), in order to represent the variability of the bare soil temperature bounded by its wet and dry endmembers. Advanced regression tools using spectral bands, have been successfully used in different studies produce better disaggregation results than simple polynomial functions (Ghosh and Joshi, 2014)

Recently, some studies have attempted to represent the SM effect. Liu and Zhu (2012) used a normalized multi-band drought index (NMDI) for monitoring soil and vegetation moisture, based on the absorption properties of the vegetation water in the NIR and the sensitive characteristics of water absorption differences between soil and vegetation in the short-wave infrared (SWIR). However, NMDI has inconsistent relationships with vegetation and soil moisture changes (i.e. positive correlation with vegetation water content and negative correlation with SM changes). Therefore, it poorly performed over mixed pixels of vegetation and soil. Chen et al. (2010) took into account SM variations using a soil wetness index (SWI) estimated based on the interpretation of the triangular LST-NDVI space. However, the errors were found to be larger with low fractional vegetation cover. In the same manner, Yang et al. (2010) discussed the impact of SM variations using the LST-NDVI space and assumed uniform SM conditions in a coarse pixel. Therefore this technique is only appropriate in regions where $\mathrm{SM}$ varies at large scale and in pixels with high $\mathrm{f}_{\mathrm{gv}}$. In general, the previously proposed proxies or indexes that aim to incorporate the SM effect on LST poorly performed over the areas with low vegetation cover.

In this context, a new algorithm is proposed to improve the disaggregation of LR LST by explicitly taking into the variability of $\mathrm{SM}$ at HR. Incorporating $\mathrm{SM}$ information to 
disaggregate LST has the advantage of distinguishing between the dry and the wet soil especially in areas with low vegetation cover, where the soil moisture status is the main factor controlling the LST variability. The novelty of this work is to integrate a spaceborne radarderived soil moisture proxy in the disaggregation of $1 \mathrm{~km}$ resolution LST. This research relies on the Sentinel-1 (S-1) mission, which provides C-band radar data at both high-spatial and high-temporal resolutions. The approaches are tested over an $8 \mathrm{~km}$ by $8 \mathrm{~km}$ and $12 \mathrm{~km}$ by $12 \mathrm{~km}$ semi-arid areas near Marrakech-Morocco. The chosen sites allows for testing the algorithm over a heterogonous landscape in terms of vegetation type and SM status where LST highly varies in both space and time. The methodologies are applied to aggregated Landsat LST and to MODIS LST data separately, and the HR ancillary data are derived from radar S-1 and VNIR Landsat data. Finally the disaggregated LST is evaluated at $100 \mathrm{~m}$ resolution against Landsat LST.

\section{Site description and data set 2.1. Study area}

The study areas are located in the semi-arid Haouz plain, situated near Marrakech city, in central Morocco (Fig. 1). This region is characterized by irregular and low rainfall of about $250 \mathrm{~mm} /$ year with a high evaporative demand that exceeds $1600 \mathrm{~mm} / \mathrm{year}$.

In recent years, several field campaigns and experiments have been carried out and numerous studies have been conducted over this area with different objectives related to agricultural water management (Amazirh et al., 2018, 2017; Chehbouni et al., 2008; Er-Raki et al., 2010; Jarlan L et al., 2015; Khabba et al., 2013; Duchemin et al., 2008).

The first site is an irrigated agricultural zone (called R3) known by its heterogeneity and occupied by different culture types (alfalfa, wheat, olive, orange and horticulture), where wheat crops is the dominating culture $(50 \%)$. Flood irrigation is the main irrigation mode used in this area.

The second area is a rainfed agricultural area (called Sidi Rahal) mainly dominated by trees (about 80\%) while the remaining surface is comprised of bare soil, small forest and impervious surfaces (e.g., buildings and roads). The dark area mainly represents parcels maintained in bare soil conditions (due to a lack of rainfall in late December) and building. Based on soil analysis (Er-Raki et al., 2007), soil texture is clayey and sandy in the majority of fields within the R3 and Sidi Rahal areas, respectively. 

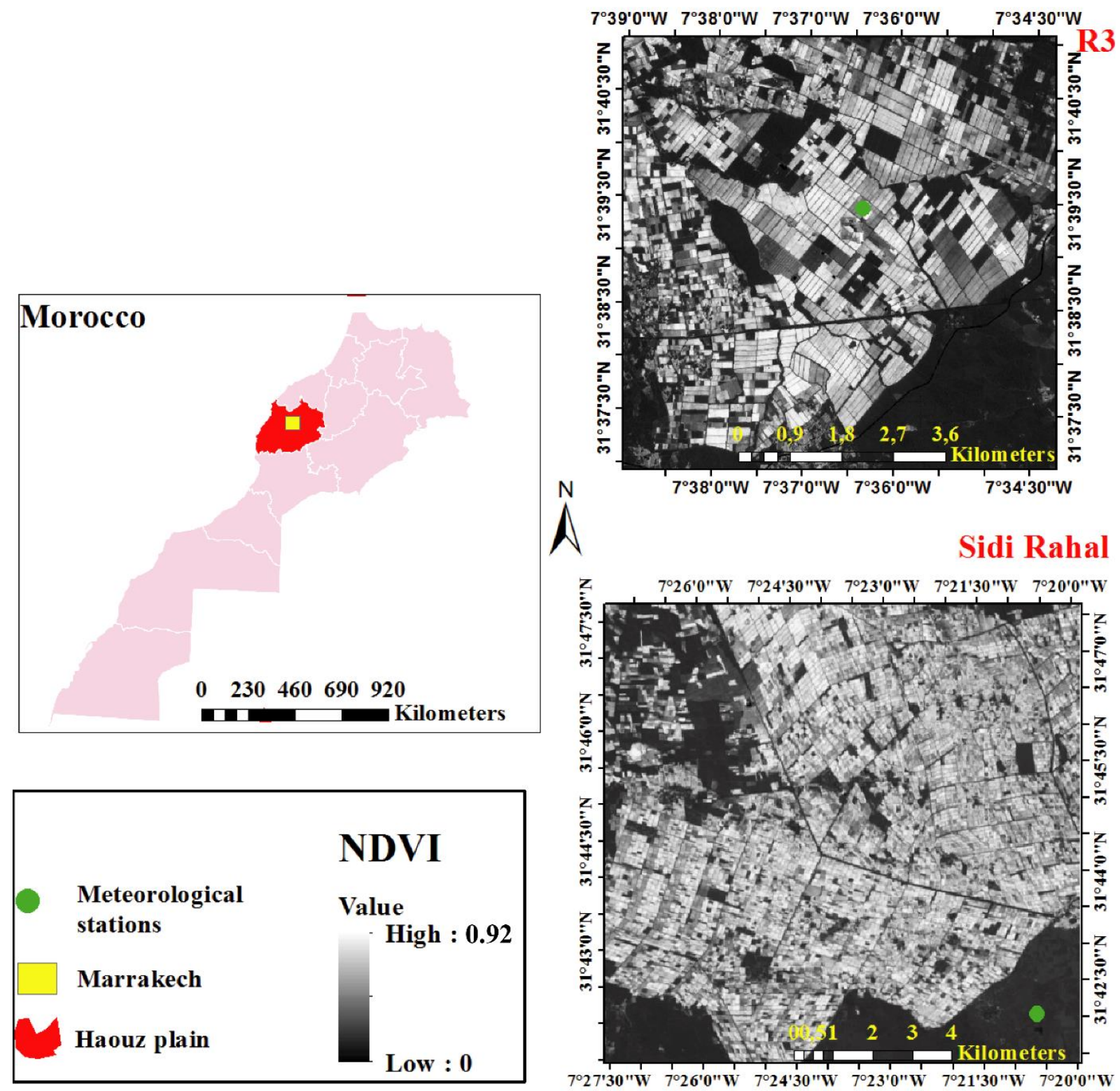

Fig. 1. Location of Marrakech in the Tensift Al Haouz region, Morocco (left) and the study areas (right) including the weather station installed (green circles) during the 2015-2016 agricultural season. The images are derived from Landsat data, the 07 February and the 24 July for Sidi Rahal and $R 3$ sites, respectively.

\subsection{Ground data}

Two automatic meteorological stations have been installed, one over an alfalfa cover in the R3 perimeter and another over a rainfed wheat crop at the Sidi Rahal site providing local data including air temperature ( $\mathrm{T}_{\text {air }}$ ), relative humidity (rha) wind speed (ua), wind direction and global solar is located in a rainfed wheat crop (bare soil during the study) in the lower right plot (Fig.1).

\subsection{Satellite data}


172 In this study, seven dates of quasi coincident VNIR/thermal and radar images were used

173 (Table 1). The L-7 and L-8 images were downloaded from the USGS website, which freely

174

175 provides surface reflectances and thermal radiances data in different spectral bands. The level1 products are calibrated radiometrically and orthorectified using digital elevation model. The revisit time of each sensor is 16 days. Combining both satellites potentially (in cloud free conditions) provides optical data every 8 days. S-1 mission is composed of a constellation of two twin satellites. Both S-1A and S-1B operate in C-band synthetic aperture radar (SAR), providing data in four operational modes (Strip Map, Interferometric Wide Swath, Extra wide swath and Wave) and different polarizations for all modes. The S-1 constellation offers data with high revisit frequency (every 3-6 days).

\subsubsection{High resolution reflectances}

In our feasibility study, Landsat VNIR data are used because the Landsat LST is, in any case, required for evaluating the disaggregated LST. In real-life, however, the disaggregation approaches should be implemented using high spatio-temporal resolution VNIR data collected from Sentinel-2. The VNIR Landsat reflectances are aggregated at $100 \mathrm{~m}$ resolution, consistent with Landsat LST spatial resolution. Surface reflectances are used to calculate the NDVI, defined as the ratio of the difference between the spectral reflectance measurements acquired in NIR and red to their sum. The fractional green vegetation cover is estimated from an empirical relationship with NDVI (Gutman and Ignatov, 1998):

$$
f_{g v}=\frac{N D V I-N D V I}{b s}
$$

Where $\mathrm{NDVI}_{\mathrm{gv}}$ and $\mathrm{NDVI}_{\mathrm{bs}}$ are the NDVI over full-cover green vegetation and bare soil, respectively. The NDVI end-members are derived from the time series of Landsat data as the minimum and maximum value of the $100 \mathrm{~m}$ resolution NDVI within the whole selected areas for the bare soil and full-cover green vegetation case, respectively.

\subsubsection{Thermal infrared (TIR) data}

\subsubsection{MODIS data}

The daily $1 \mathrm{~km}$ resolution LST (version 6) MOD11A1 product is available through the U.S. Land Processes Distributed Active Archive Center (LP DAAC, https://lpdaac.usgs.gov/). The generalized split-window algorithm (Wan, 1996; Wan et al., 2002) has been used to retrieve MODIS LST products and a correction step was performed using the surface band emissivity 
202

203

204

205

206

207

208

209

210

211

212

213

214

215

216

217

218

219

220

221

222

223

224

225

226

227

228

229

230

231

232

233

provided also by MODIS spectral data. The LST data were re-projected from sinusoidal to geographic latitude/longitude using the Universal Transverse Mercator (UTM), Zone 29N, World Geodetic System (WGS) 84 coordinate system.

\subsubsection{Landsat data}

L-7 and L-8 sensors provide TIR data with a spatial resolution of $60 \mathrm{~m}$ and $100 \mathrm{~m}$, respectively. The TIR radiance is used to calculate LST. To this end, all the followed correction steps and the processing chain are described in Tardy et al. (2016).

The L-7 LST is averaged (aggregated) at $100 \mathrm{~m}$ resolution, which is the lowest spatial resolution between S-1 and Landsat data. Note that the reliability of the Landsat-derived LST was checked in Amazirh et al. (2017) by comparing remotely sensed LST with local in situ measurements (not shown here) at two TIR stations located within the study area. A relatively good match between satellite and ground LST data was obtained for both sites with an error smaller than 1.0 and $2.4{ }^{\circ} \mathrm{C}$.

The Landsat LSTs are linearly aggregated at $1 \mathrm{~km}$ resolution to match the spatial resolution of MODIS observations. The linear averaging technique (without accounting for the nonlinear relationship between physical temperature and radiance) is chosen based on the work of (Liu et al., 2006), which found that the maximum difference between the temperature aggregated using different upscaling approaches is $0.2^{\circ} \mathrm{C}$.

\subsubsection{Sentinel-1 radar data}

Between January 01 and December 31 2016, among the 49 images collected over the study area, seven were approximately coincident (with a 1-day precision) with clear sky Landsat images (Table 1). The S-1 level 1 SAR scenes were collected in both ascending and descending pass directions over the study site. The S-1 satellite provides data in both VV and VH polarization modes at an incidence angle of $40^{\circ}$ over the study area. The S-1 Ground Range Detected (GRD) images were acquired in interferometric wide swath mode (IW), with an original spatial resolution of $5 \mathrm{~m}$ by $20 \mathrm{~m}$. Several processing steps are applied before using the original S-1 data, in order to convert the radar signal to a backscatter coefficient using the Sentinel Application Platform (SNAP). A detailed description of the retrieved processing steps is reported in Amazirh et al. (2018). Among the two available polarizations, the VV polarization is selected in this study for downscaling LST. The rationale behind using VV instead of VH, is that in Amazirh et al. (2018), the VV polarization was found to be more sensitive to SM variability over bare soil than $\mathrm{VH}$ over the same study area. S-1 VV 
234 backscatter $\left(\sigma_{\mathrm{vv}}^{0}\right)$ is aggregated at $100 \mathrm{~m}$ resolution, consistent with Landsat LST spatial 235 resolution.

236 Table 1: The seven dates between January 01 and December 31, 2016 when S-1data are collected one 237 day after Landsat data (in clear sky conditions) are selected.

\begin{tabular}{cc}
\hline $\mathbf{S}-1 \boldsymbol{\sigma}_{\mathbf{v v}}^{\mathbf{0}}$ & Landsat LST and NDVI \\
\hline 07 January 2016 & 06 January 2016* \\
\hline 08 February 2016 & 07 February $2016^{*}$ \\
\hline 19 March & 18 March $^{+}$ \\
\hline 07 June & 06 June $^{+}$ \\
\hline 01 July & 30 June * $^{*}$ \\
\hline 25 July & 24 July \\
\hline 18 August & 17 August * \\
\hline
\end{tabular}

239 Table 2 summarizes the characteristics of the satellite data products used as input to, and for validation of disaggregation approaches.

Table 2: Technical characteristics of satellite products.

\begin{tabular}{|c|c|c|c|c|}
\hline Sensors/Mission & Acquisition Time & Bands & $\begin{array}{c}\text { Spatial } \\
\text { resolution }(\mathbf{m})\end{array}$ & $\begin{array}{c}\text { Temporal resolution } \\
\text { (Day) }\end{array}$ \\
\hline S-1 A/B & $\begin{array}{c}\text { 06:30 AM (descending) } \\
\text { and 06:30 PM } \\
\text { (ascending) }\end{array}$ & SAR/ C-band & 20 & $3-6$ \\
\hline L-7/-8 & $\sim 11: 30 \mathrm{AM}$ & $\begin{array}{l}\text { - VNIR (L-7: B3 \& B4 ; L-8:B4 } \\
\text { \& B5) } \\
\text { - TIR (B6 for L-7 and B10 \& B11 } \\
\text { for L-8) }\end{array}$ & $\begin{array}{l}60 \text { and } 100 \text { for } \\
\text { TIR } \\
30 \text { for VNIR }\end{array}$ & 8 \\
\hline MODIS/Terra & $\sim 11: 30 \mathrm{AM}$ & - TIR & $\sim 1000$ & 1 \\
\hline
\end{tabular}

Fig. 2 shows an example of the spatial variability of LST, $f_{\mathrm{gv}}$ and $\sigma_{\mathrm{vv}}^{0}$ over the study site. Two growing stages (initial, and mid-season) are chosen for illustration purposes. For the initial stage most of the fields are under bare soil conditions with low fraction of green vegetation and the backscatter coefficient is mainly influenced by the SM and roughness, while LST mainly depends on atmospheric conditions and the soil water availability. During the midseason, $\mathrm{f}_{\mathrm{gv}}$ reaches its maximum value and the non-cultivated parcels generate higher value of LST $\left(40{ }^{\circ} \mathrm{C}\right)$. The spatial variability of the backscatter is attributed to a combined effect of SM and vegetation (water content). Over cultivated areas, vegetation decreases the radar signal while SM increases it. 

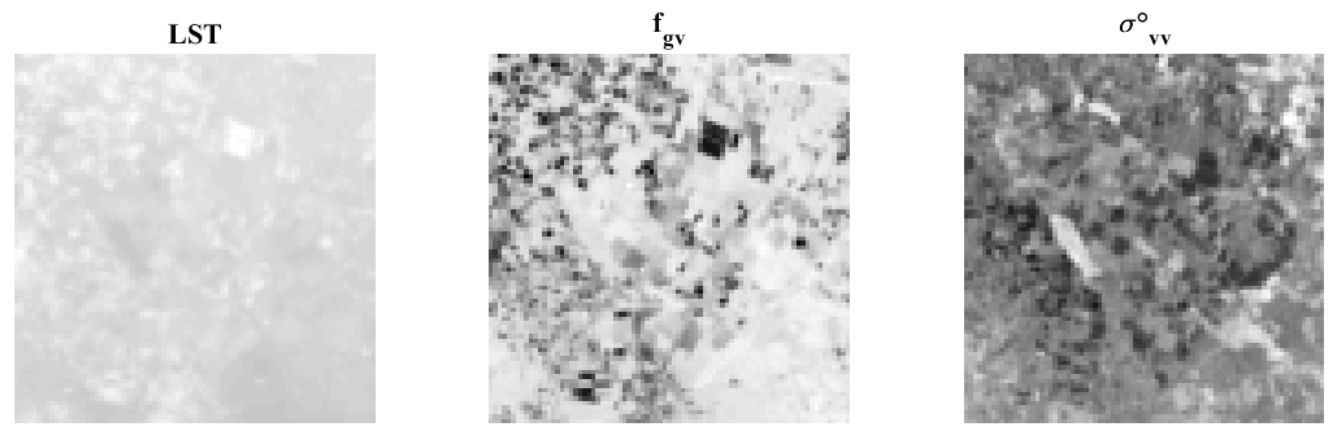

251
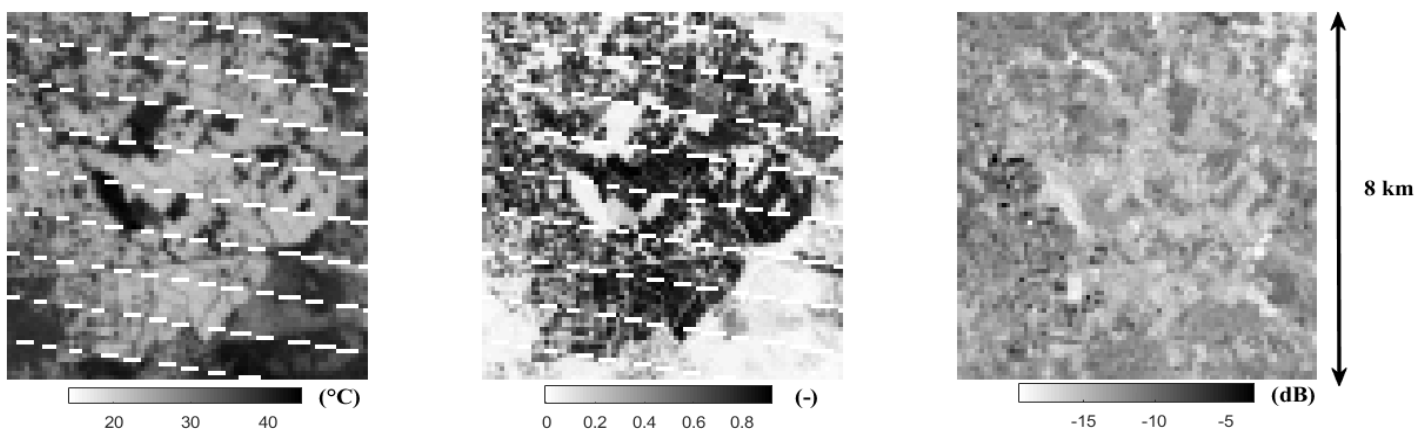

253

254

Fig.2. LST, $f_{g v}$ and $\sigma_{v v}^{0} 100 \mathrm{~m}$ resolution maps over $R 3$ area at dates corresponding to the initial and mid-season growing stages: January 06 (top) and March 18 (bottom).

\section{Disaggregation Methods}

Two disaggregation techniques are applied in this work using the same input data derived from microwave (radar) and optical (NDVI) data. The methodologies are tested over two different study areas, including a range of conditions (land use, soil hydric status,...). The two versions are named multi-linear regression (MLR) and radiative transfer model (RTM) techniques. Both methodologies are based on a scale invariant relationship between LST and other ancillary variables, which are statistically correlated to LST pixel by pixel. In this work the disaggregation methodologies were applied to aggregated Landsat derived-LST (as a first assessment by minimizing uncertainties in LR LST) and then applied to MODIS/Terra LST (as a real case application). The $100 \mathrm{~m}$ resolution was chosen as the target downscaling because it is the lowest spatial resolution at which all the input HR data are available. The diagram in Fig. 3 summarizes briefly the different disaggregation algorithms used in this work. 
267

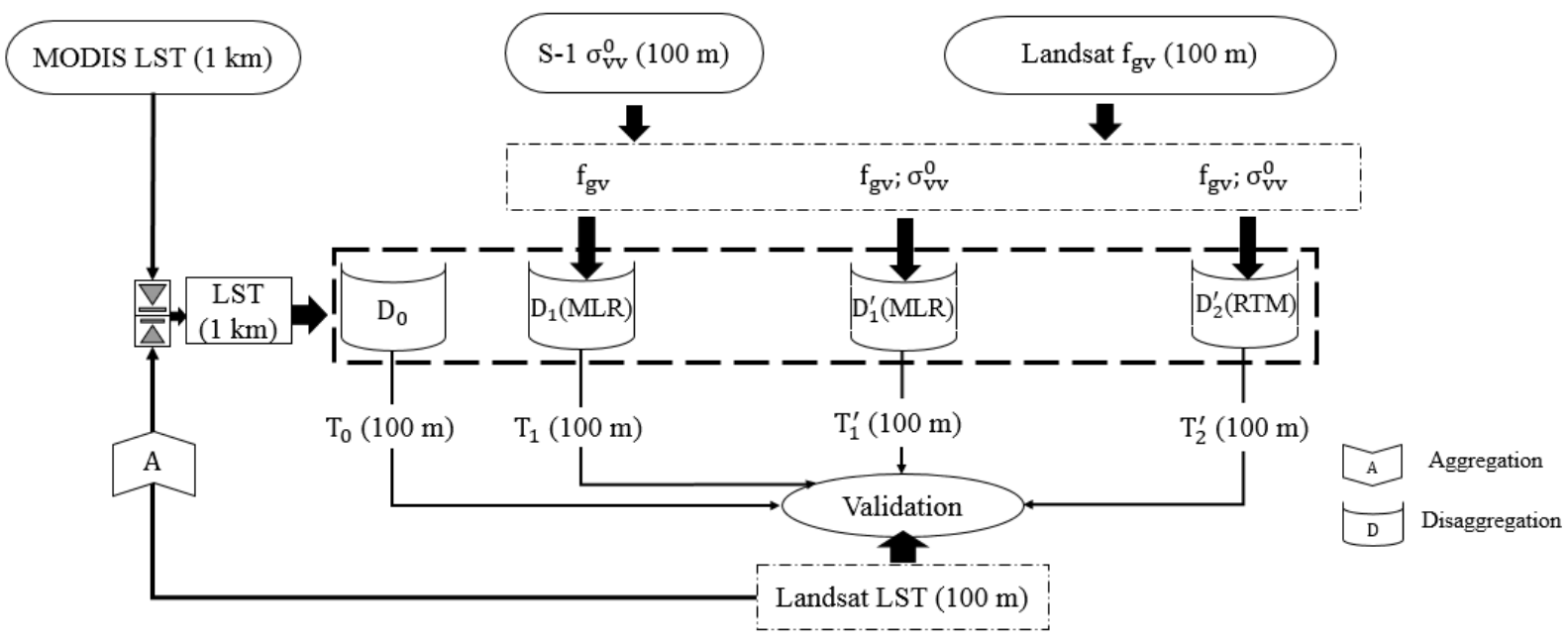

Fig.3. Diagram showing the different disaggregation algorithms and their input/output data.

D0 algorithm requires no ancillary data. By cons, D1 (MLR), D1' (MLR) and D2' (RTM) need additional data to disaggregate LST. D1 algorithm is based on $\mathrm{f}_{\mathrm{gv}}$ only, while D1' and D2' are based on both $f_{\mathrm{gv}}$ and $\sigma_{\mathrm{vv}}^{0}$. A description of the MLR and RTM techniques is presented in the following subsections.

\subsection{Multi-linear regressions (MLR) technique}

The MLR technique is based on a linear regression at LR between LST and auxiliary data. This method was firstly developed by Kustas et al. (2003) using NDVI as a biophysical indicator of LST. In practice, a least-squares fit is performed between LST $(T)$ and the $f_{g v}$ aggregated at $1 \mathrm{~km}$. Formally, The D1 algorithm is expressed as:

$\mathrm{D}_{1}$

$$
\mathrm{T}_{1}=\mathrm{LST}_{\mathrm{km}}+\mathrm{a} \times\left(\mathrm{f}_{\mathrm{gv}}-\mathrm{f}_{\mathrm{gv}, \mathrm{km}}\right)
$$

with a being the regression coefficient of the least squares regression between $\mathrm{LST}_{\mathrm{km}}$ and $\mathrm{f}_{\mathrm{gv}, \mathrm{km}}$, and $\mathrm{LST}_{\mathrm{km}}$ and $\mathrm{f}_{\mathrm{gv}, \mathrm{km}}$ the LR LST and the aggregated $\mathrm{f}_{\mathrm{gv}}$, respectively.

The $\mathrm{D}_{1}^{\prime}$ disaggregation algorithm is proposed to improve the $\mathrm{D} 1$ algorithm by inserting additional information about SM (information derived from the S-1 data). A MLR is performed between LST, $\mathrm{f}_{\mathrm{gv}}$ and $\sigma_{\mathrm{vv}}^{0}$ at LR:

$\mathrm{D}_{1}^{\prime}$

$$
\mathrm{T}_{1}^{\prime}=\mathrm{LST}_{\mathrm{km}}+\mathrm{a}^{\prime} \times\left(\mathrm{f}_{\mathrm{gv}}-\mathrm{f}_{\mathrm{gv}, \mathrm{km}}\right)+\mathrm{b}^{\prime} \times\left(\sigma_{\mathrm{vv}}^{0}-\sigma_{\mathrm{vv}, \mathrm{km}}^{0}\right)
$$

With $\mathrm{a}^{\prime}$ and $\mathrm{b}^{\prime}$ being the slopes of the MLR equation at kilometric resolution, and $\sigma_{\mathrm{vv}, \mathrm{km}}^{0}$ the aggregated $\sigma_{\mathrm{vv}}^{0}$. 


\subsection{RTM technique}

The RTM approach (Merlin et al. 2012) is based on the equation which is formally written as:

$\mathrm{D}_{2}^{\prime}$

$$
\mathrm{T}_{2}^{\prime}=\mathrm{LST}_{\mathrm{km}}+\Delta \mathrm{T}_{2}^{\prime}
$$

With the corrective term $\Delta \mathrm{T}_{2}^{\prime}$ estimated using a RTM forced by HR input data derived from $\mathrm{f}_{\mathrm{gv}}$ and $\sigma_{\mathrm{vv}}^{0}$ :

$$
\Delta \mathrm{T}_{2}^{\prime}=\mathrm{T}_{\mathrm{sim}}\left(\mathrm{f}_{\mathrm{gv}}, \mathrm{P}_{\sigma_{\mathrm{vv}}^{0}}\right)-\left\langle\mathrm{T}_{\mathrm{sim}}\left(\mathrm{f}_{\mathrm{gv}}, \mathrm{P}_{\sigma_{\mathrm{vV}}^{0}}\right)\right\rangle_{\mathrm{KM}}
$$

With $\mathrm{T}_{\text {sim }}$ being the LST simulated by the RTM, \langle\rangle$_{\mathrm{KM}}$ the resampling function from $100 \mathrm{~m}$ to $1 \mathrm{~km}$ resolution and $\mathrm{P}_{\sigma_{\mathrm{VV}}^{0}}$ a $\mathrm{SM}$ proxy derived from $\mathrm{S}-1$ data:

$$
P_{\sigma_{\mathrm{vV}}^{0}}=\frac{\sigma_{\mathrm{vv}}^{0}-\sigma_{\mathrm{vv}, \min }^{0}}{\sigma_{\mathrm{vv}, \text { max }}^{0}-\sigma_{\mathrm{vv}, \text { min }}^{0}}
$$

where $\sigma_{\mathrm{vv}, \max }^{0}$ and $\sigma_{\mathrm{vv} \text {, min }}^{0}$ are the maximum and minimum $\sigma_{\mathrm{vv}}^{0}$ during the season and over the study area. $\sigma_{\mathrm{vv}, \min }^{0}$ and $\sigma_{\mathrm{vv}, \max }^{0}$ hence represent the driest and the wettest pixels observed at $100 \mathrm{~m}$ resolution over the study site, respectively.

The $\mathrm{T}_{\text {sim }}\left(\mathrm{f}_{\mathrm{gv}}, \mathrm{P}_{\sigma_{\mathrm{vv}}^{0}}\right)$ is calculated as:

$$
\mathrm{T}_{\mathrm{sim}}\left(\mathrm{f}_{\mathrm{gv}}, \mathrm{P}_{\sigma_{\mathrm{vv}}^{0}}\right)=\mathrm{f}_{\mathrm{gv}} \times \mathrm{T}_{\mathrm{fc}, \mathrm{gv}}+\left(1-\mathrm{f}_{\mathrm{gv}}\right) \times \mathrm{T}_{\mathrm{bs}}^{\mathrm{sm}}
$$

With $\mathrm{T}_{\mathrm{fc}, \mathrm{gv}}$ is the temperature of pixel with fully-covered vegetation and $\mathrm{T}_{\mathrm{bs}}^{\mathrm{sm}}$ the bare soil temperature estimated using a linearized RTM:

$$
\mathrm{T}_{\mathrm{bs}}^{\mathrm{sm}}=\mathrm{T}_{\mathrm{bs}, \mathrm{w}} \times \mathrm{P}_{\sigma_{\mathrm{vv}}^{0}}+\mathrm{T}_{\mathrm{bs}, \mathrm{d}} \times\left(1-\mathrm{P}_{\sigma_{\mathrm{vv}}^{0}}\right)
$$

Where $\mathrm{T}_{\mathrm{bs}, \mathrm{w}}$ and $\mathrm{T}_{\mathrm{bs}, \mathrm{d}}$ are the wet and dry bare soil temperatures, respectively. Note that the temperature end-members $\left(\mathrm{T}_{\mathrm{fc}, \mathrm{gv}}, \mathrm{T}_{\mathrm{bs}, \mathrm{w}}\right.$ and $\left.\mathrm{T}_{\mathrm{bs}, \mathrm{d}}\right)$ are estimated based on a synergy between the LST- $f_{\mathrm{gv}}$ space, the LST- $\sigma_{\mathrm{vv}}^{0}$ space and a soil energy balance (EB) model. The sub-section below details the steps followed for estimating $\sigma_{\mathrm{vv}}^{0}$ and temperature endmembers.

\subsubsection{End-members estimation}

Before applying the disaggregation methodologies, the endmembers required in the RTM method, namely the three temperatures $\left(\mathrm{T}_{\mathrm{fc}, \mathrm{gv}}, \mathrm{T}_{\mathrm{bs}, \mathrm{d}}\right.$ and $\left.\mathrm{T}_{\mathrm{bs}, \mathrm{w}}\right)$ and the three backscatter 
311 coefficients (green vegetation $\sigma_{\mathrm{vv}, \mathrm{gv}}^{0}$, bare dry soil $\sigma_{\mathrm{vv}, \mathrm{bs}, \mathrm{d}}^{0}$ and bare wet soil $\sigma_{\mathrm{vv}, \mathrm{bs}, \mathrm{w}}^{0}$ ), are determined from available information. Temperature endmembers vary from date to date depending on the growing stage of vegetation and the soil hydric status over differences landscapes within the selected areas.

\subsubsection{Backscatter endmembers}

Fig. 4 presents the spatial variability of $\sigma_{\mathrm{vv}}^{0}$ pixel by pixel compared to $\mathrm{f}_{\mathrm{gv}}$. Based on the observed $\sigma_{\mathrm{vv}}^{0}-\mathrm{f}_{\mathrm{gv}}$ space, the vegetation backscatter coefficient $\sigma_{\mathrm{vv}, \mathrm{gv}}^{0}$ is estimated as the $\sigma_{\mathrm{vv}}^{0}$ corresponding to $\mathrm{f}_{\mathrm{gv}}=1$, vertex $\mathrm{C}\left(1, \sigma_{\mathrm{vv}, \mathrm{gv}}^{0}\right)$ in the $\sigma_{\mathrm{vv}}^{0}-\mathrm{f}_{\mathrm{gv}}$ space. The backscatter of bare soil in dry $\left(\sigma_{\mathrm{vv}, \mathrm{bs}, \mathrm{d}}^{0}\right)$ and wet $\left(\sigma_{\mathrm{vv}, \mathrm{bs}, \mathrm{w}}^{0}\right)$ conditions is considered as the minimum and maximum backscatters observed at low $\mathrm{f}_{\mathrm{gv}}(<0.2)$, vertex $\mathrm{A}\left(0, \sigma_{\mathrm{vv}, \mathrm{bs}, \mathrm{d}}^{0}\right)$ and $\mathrm{B}\left(0, \sigma_{\mathrm{vv}, \mathrm{bs}, \mathrm{w}}^{0}\right)$, respectively.
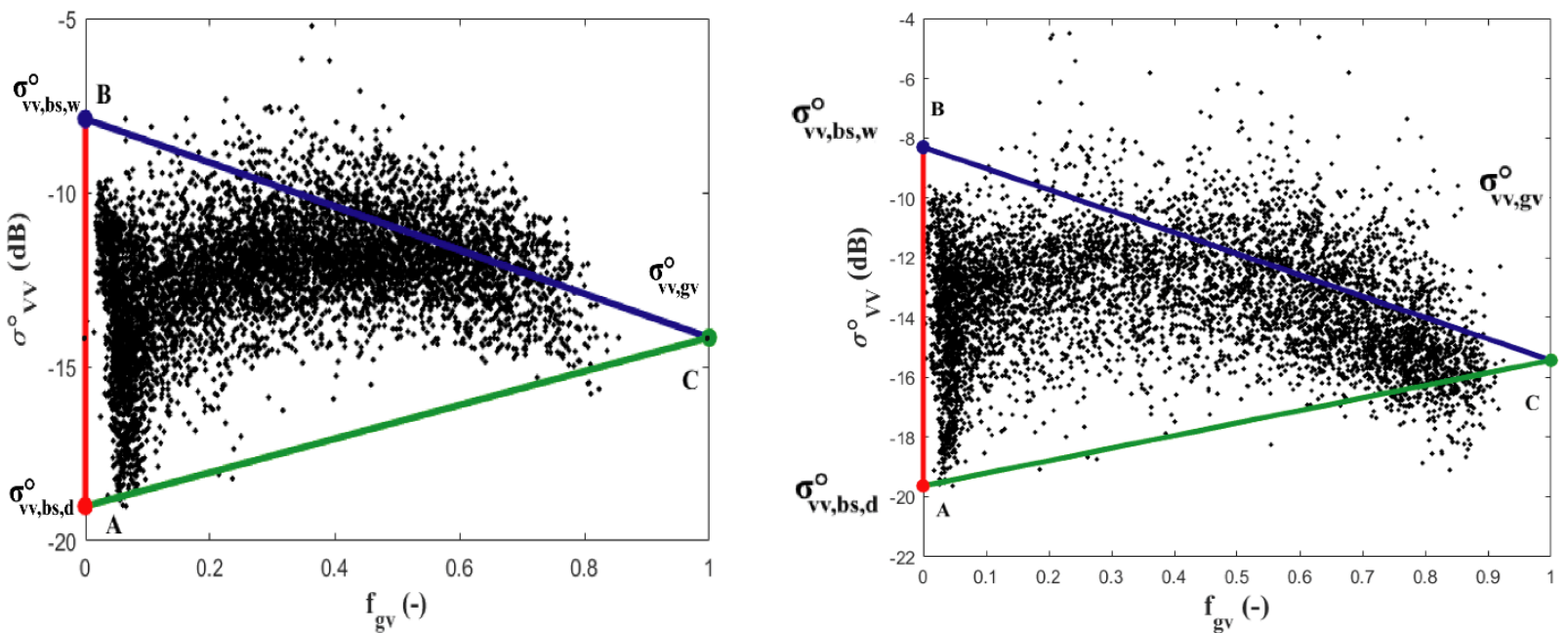

Fig.4. Identification of the $\sigma_{v v}^{0}$ end-members using the $S$-1 backscatter plotted against fractional of green vegetation cover $f_{g v}$ space for data on February 07 (left) and March 18 (right) over R3 site.

\subsubsection{LST endmembers}

In this study, the LST at HR is assumed to be unknown and therefore, extreme temperatures should be derived from LR LST and possibly other ancillary (meteorological, $\mathrm{f}_{\mathrm{gv}}$ ) data. Two different techniques are combined to estimate the LST endmembers: the contextual LST- $\mathrm{f}_{\mathrm{gv}}$ space and an EB model forced by available meteorological data (Amazirh et al., 2018). In order to estimate soil extreme temperatures independently of remote sensing data a soil EB model is run to estimate $\mathrm{T}_{\mathrm{bs}, \mathrm{w}}$ and $\mathrm{T}_{\mathrm{bs}, \mathrm{d}}$. In practice, the wet and dry conditions are simulated by setting the evaporation resistance $r_{s s}$ values equal to zero and infinity, respectively. The EB model is outlined in the appendix. 
333 On some days, the maximum temperature estimated by EB modelling appears relatively low compared to the maximum (both HR and LR) observed LST especially on the hottest days (summer) as founded in Amazirh et al. (2018). This is explained by the fact that the meteorological data used as forcing to EB model are collected at a wet alfalfa site, thus underestimating the 2-m air temperature over very dry and hot surface conditions. To correct for such a slight underestimation, the $\mathrm{T}_{\mathrm{bs}, \mathrm{d}}$ is set to the maximum between the maximum value $\left(\mathrm{T}_{\max }\right)$ observed at LR and EB estimation:

$$
\mathrm{T}_{\mathrm{bs}, \mathrm{d}}=\max \left[T_{\max }, E B\left(r_{s s}=\infty\right)\right]
$$

The temperature of full cover vegetation $\left(\mathrm{T}_{\mathrm{fc}, \mathrm{gv}}\right)$ is set to the air temperature (Bastiaanssen et al., 1998; Gillies and Carlson, 1995; Merlin, 2013; Roerink et al., 2000; Stefan et al., 2015).

A visual representation of the LST- $\mathrm{f}_{\mathrm{gv}}$ and LST- $\sigma_{\mathrm{vv}}^{0}$ spaces at a LR and HR are plotted in Fig.5. The LST- $f_{\mathrm{gv}}$ space identifies three extremes values for $\mathrm{f}_{\mathrm{gv}}(0,1)$, while the LST- $\sigma_{\mathrm{vv}}^{0}$ space is surrounded by the three extremes backscatter values $\left(\sigma_{\mathrm{vv}, \mathrm{gv}}^{0}, \sigma_{\mathrm{vv}, \mathrm{bs}, \mathrm{d}}^{0}\right.$ and $\left.\sigma_{\mathrm{vv}, \mathrm{bs}, \mathrm{w}}^{0}\right)$ derived previously from the $\sigma_{\mathrm{vv}}^{0}-\mathrm{f}_{\mathrm{gv}}$ space. Note that the triangle formed in the sigma- $\mathrm{f}_{\mathrm{gv}}$ space is not as well defined as in the LST- $f_{g v}$ space. In fact, the spatial correlation between sigma and $\mathrm{f}_{\mathrm{gv}}$ is affected by variabilities of both $\mathrm{SM}$ and soil roughness. Therefore, $\sigma_{\mathrm{vv}, \mathrm{bs}, \mathrm{d}}^{0}$ more precisely corresponds to a smooth (low roughness) dry soil and larger sigma values are expected over dry bare soil pixels with larger surface roughness (the data points on the other side of the AB segment).

The point A in Fig.5 in the low resolution (aggregated LST) case is estimated using the soil energy balance model, which estimates LST in dry soil condition using meteorological data only i.e. independently from Landsat observations. For that reason, the simulated dry soil temperature is hence not necessarily equal to the maximum value observed within the study area from Landsat LST. 

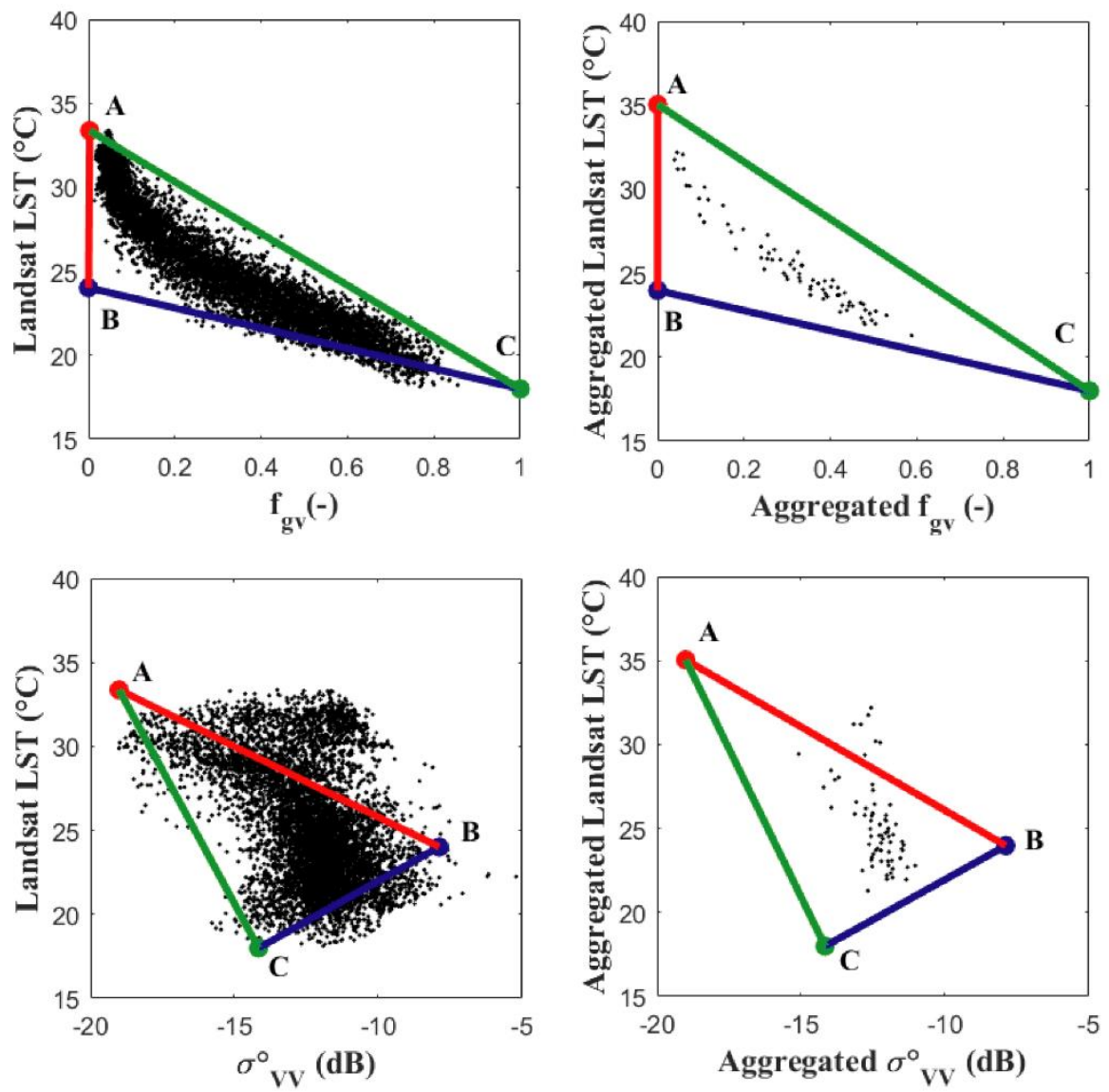

Fig.5. Scatterplot of $L S T-f_{g v}$ and $L S T-\sigma_{v v}^{0}$ spaces at $100 \mathrm{~m}$ (left) and $1 \mathrm{~km}$ (right) resolution. In the LR case, extreme temperatures are estimated using a soil EB model on February 07 over R3 site.

\section{Results}

The disaggregation approaches MLR (D1 and D1') and RTM (D2') are applied to the seven dates when all the satellite data are available. The disaggregated LST is evaluated against Landsat LST and in each case, disaggregation results are compared with those obtained in the no-disaggregation case (D0). A stepwise approach is presented by using the (1 km resolution) aggregated Landsat LST as the LR LST input prior to the application to MODIS LST.

\subsection{Application to aggregated Landsat-7/-8 data}

As a first assessment, the disaggregation approaches are applied to aggregated Landsat LST. Moreover, in the case of RTM (D2'), the LST end-members are estimated from the spaces built from HR data in order to reduce possible uncertainties. The disaggregation results are evaluated visually and quantitatively using the $100 \mathrm{~m}$ Landsat LST image as reference. Fig. 6 shows the LST images obtained from D0, D1, D1' and D2' for the six dates over Sidi Rahal rainfed site. The high spatial heterogeneity in soil properties and the land use over the selected 
374 areas induces strong variations in LST at the HR. All three D1, D1' and D2' algorithms

375 provide more variability of LST than D0 algorithm which does not take into account the

376 spatial variability at HR. It is also observed that the boxy artifact, meaning the block effect

377 that still remains in the disaggregated LST at the LR (Agam et al., 2007b; Merlin et al., 2010),

378 is reduced for D2'.
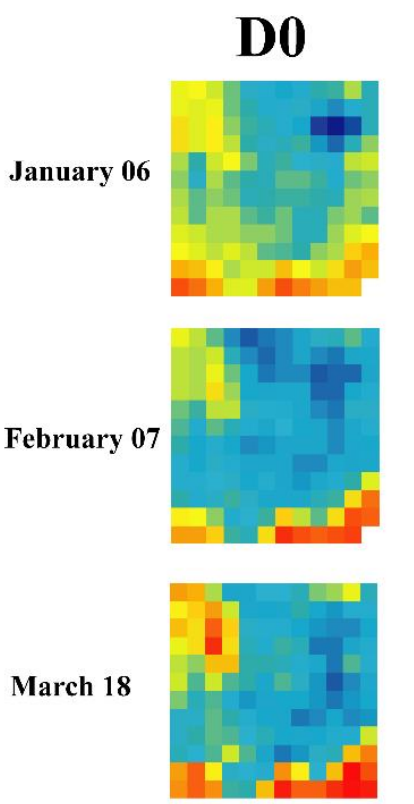

June 30
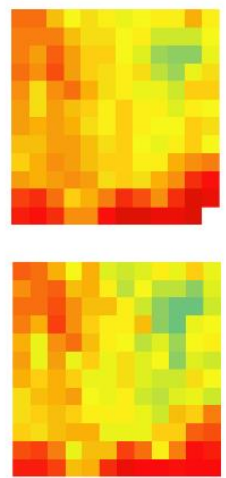

July 24

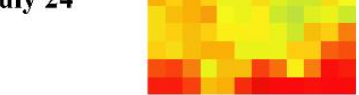

August 17

379

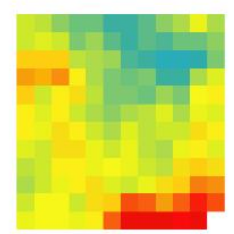

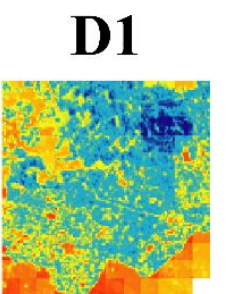
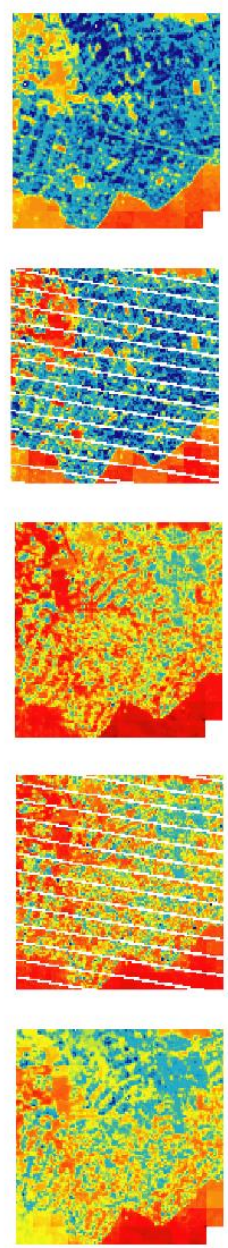

D1'
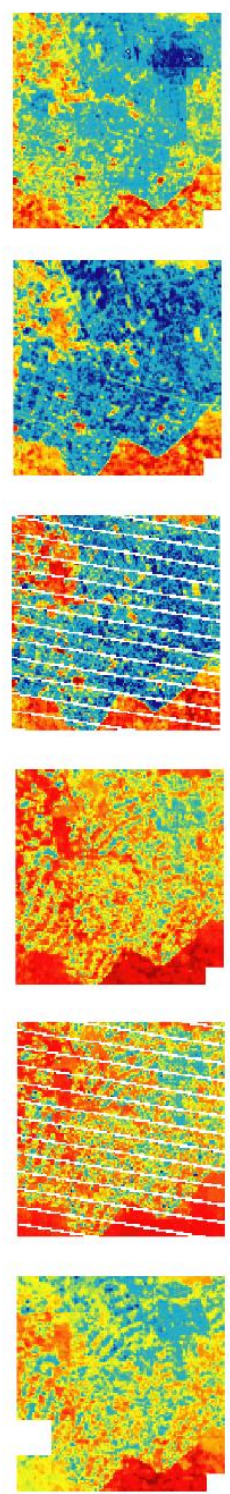

D2'
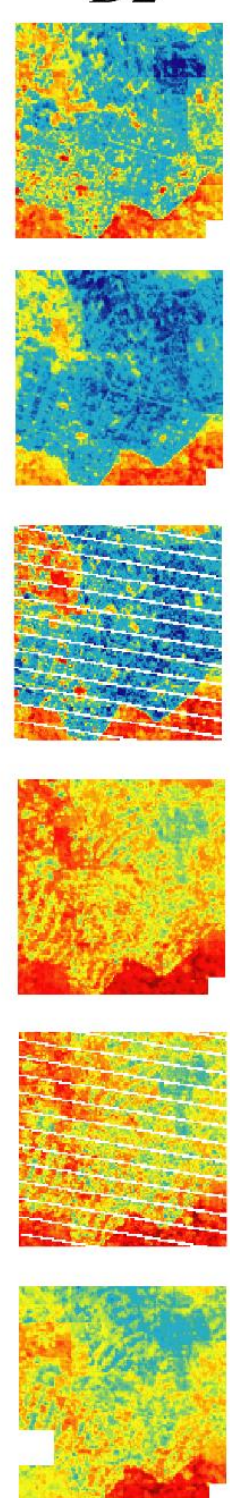
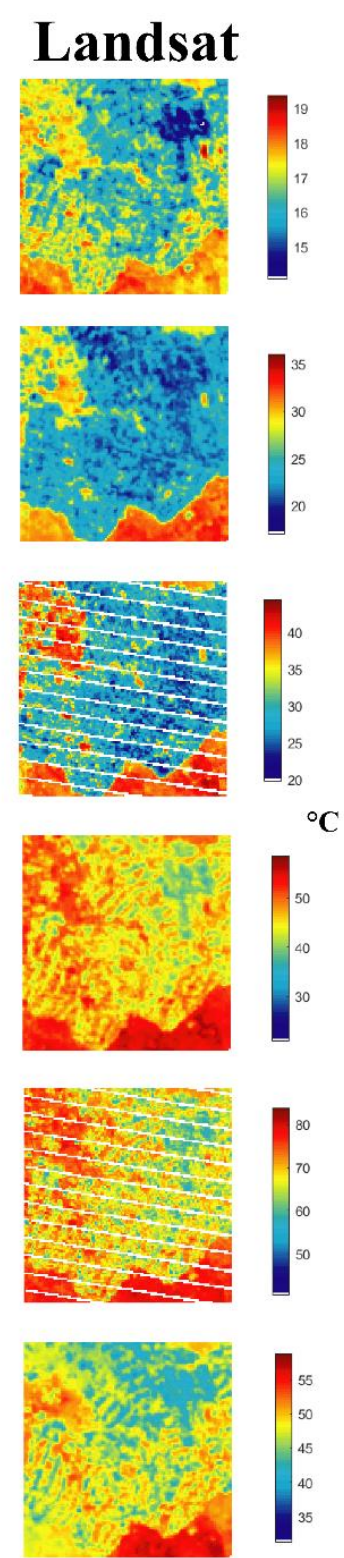

Fig.6. Maps of the LR (Landsat-aggregated) LST disaggregated by the four algorithms compared to the Landsat reference HR LST on six selected clear dates separately over Sidi Rahal area. 


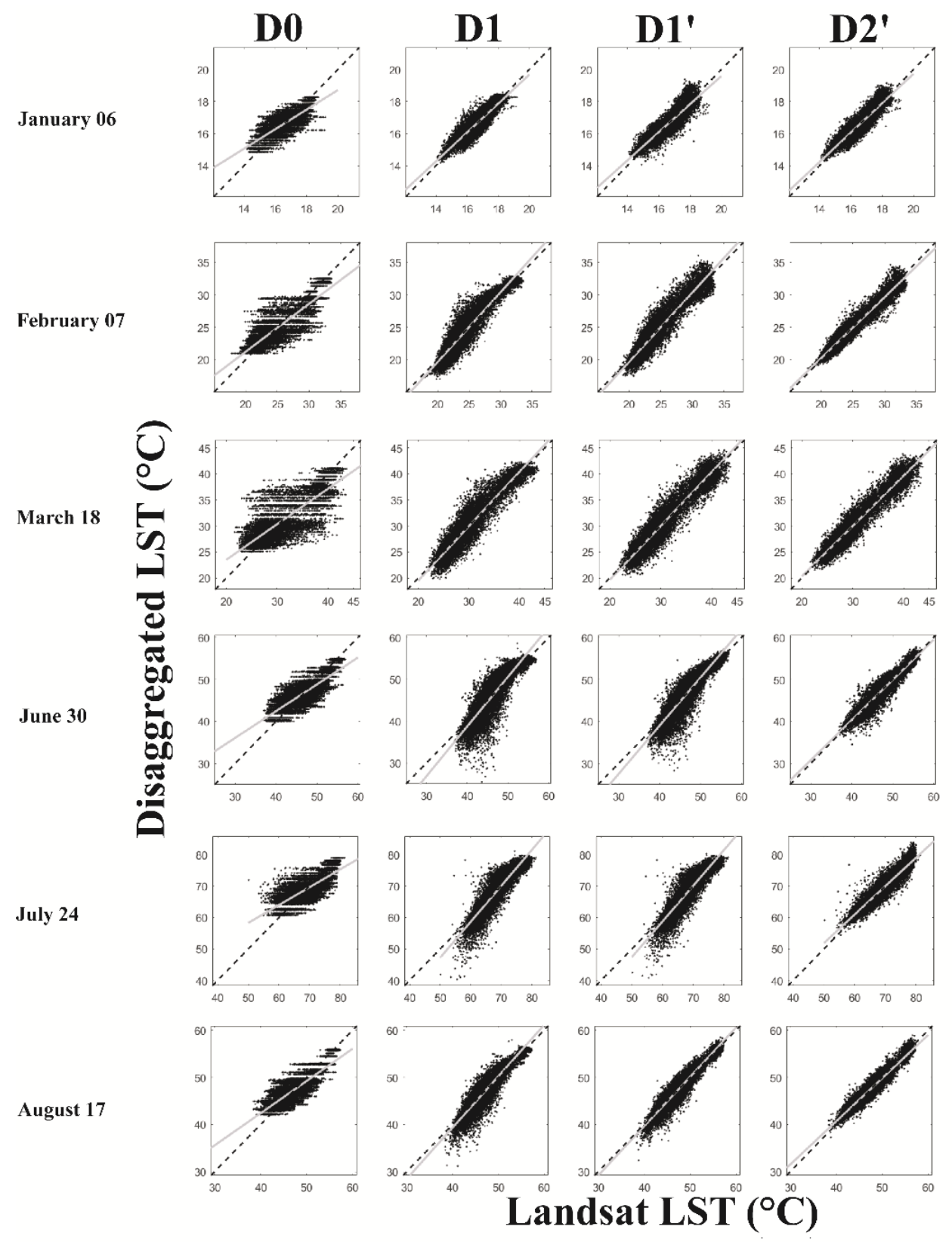

Fig. 7. Comparison between the LST disaggregated using each algorithm against the HR Landsat LST over Sidi Rahal area.

385 Table 3: Summary statistics of the disaggregation algorithms. Temperature endmembers are estimated 386 from HR Landsat data over the Sidi Rahal site.

\begin{tabular}{|c|c|c|c|c|c|c|c|c|c|c|c|c|}
\hline \multirow{2}{*}{ Date } & \multicolumn{4}{|c|}{$\mathbf{R}(-)$} & \multicolumn{4}{|c|}{ RMSE $\left({ }^{\circ} \mathrm{C}\right)$} & \multicolumn{4}{|c|}{ Slope (-) } \\
\hline & D0 & D1 & D1' & D2' & D0 & D1 & D1' & D2' & D0 & D1 & D1' & D2' \\
\hline February 07 & 0.87 & 0.94 & 0.95 & 0.97 & 1.68 & 1.31 & 1.25 & 0.82 & 0.73 & 1.07 & 1.06 & 0.94 \\
\hline March 18 & 0.83 & 0.95 & 0.95 & 0.96 & 2.94 & 1.79 & 1.69 & 1.39 & 0.68 & 1.04 & 1.03 & 0.96 \\
\hline June 30 & 0.81 & 0.88 & 0.90 & 0.95 & 2.29 & 2.67 & 2.27 & 1.30 & 0.63 & 1.18 & 1.14 & 0.95 \\
\hline July 24 & 0.75 & 0.91 & 0.91 & 0.93 & 3.34 & 2.80 & 2.72 & 1.88 & 0.56 & 1.14 & 1.13 & 0.90 \\
\hline August 17 & 0.84 & 0.92 & 0.95 & 0.96 & 1.86 & 1.63 & 1.26 & 0.99 & 0.68 & 1.08 & 1.04 & 0.91 \\
\hline
\end{tabular}




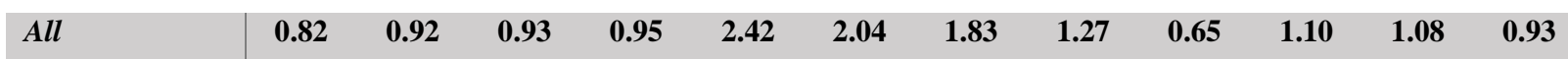

387 Results (Fig. 7) listed in Table 3, shows that the D2' performs systematically better than the 388 classical approach in all the cases, and provides more accurate results over the rainfed 389 agriculture site. $1.27{ }^{\circ} \mathrm{C}$ is the minimum mean error it has been assessed using the D2' 390 algorithm compared to $2.04{ }^{\circ} \mathrm{C}$ by using the classical D1 approach.

391 A significant underestimation is observed for the low LST values during the hottest days 392 (June 30, July 24 and August 17) using D1 and D1'. In contrast, the RTM D2' LST fits 393 correctly the Landsat observation. The most significant difference in performance is found for 394 the February 07 image, when the bare soil dominates and the soil moisture variation controls 395 the LST distribution. This means that radar data provide useful and independent information 396 about the LST variability that the $\mathrm{f}_{\mathrm{gv}}$ does not provide. The results indicate that the additional 397 SM proxy used in the RTM algorithm allows more of the variability in LST to be captured 398 over this scene.

399 The used algorithms in this paper have been tested over the $8 \mathrm{~km}$ by $8 \mathrm{~km} \mathrm{R} 3$ site, in order to 400 test the stability of the new approaches. Here we test the capacity of the new algorithm to 401 capture LST variability over the complex fields. Fig 8 show the spatial distribution and the 402 temporal variation across the season of the disaggregated and Landsat LST over the R3 site 403 for seven clear sky selected dates. We can observe a high variability of LST, which depends 404 on the spatial heterogeneity of $\mathrm{f}_{\mathrm{gv}}$ and/or SM. 


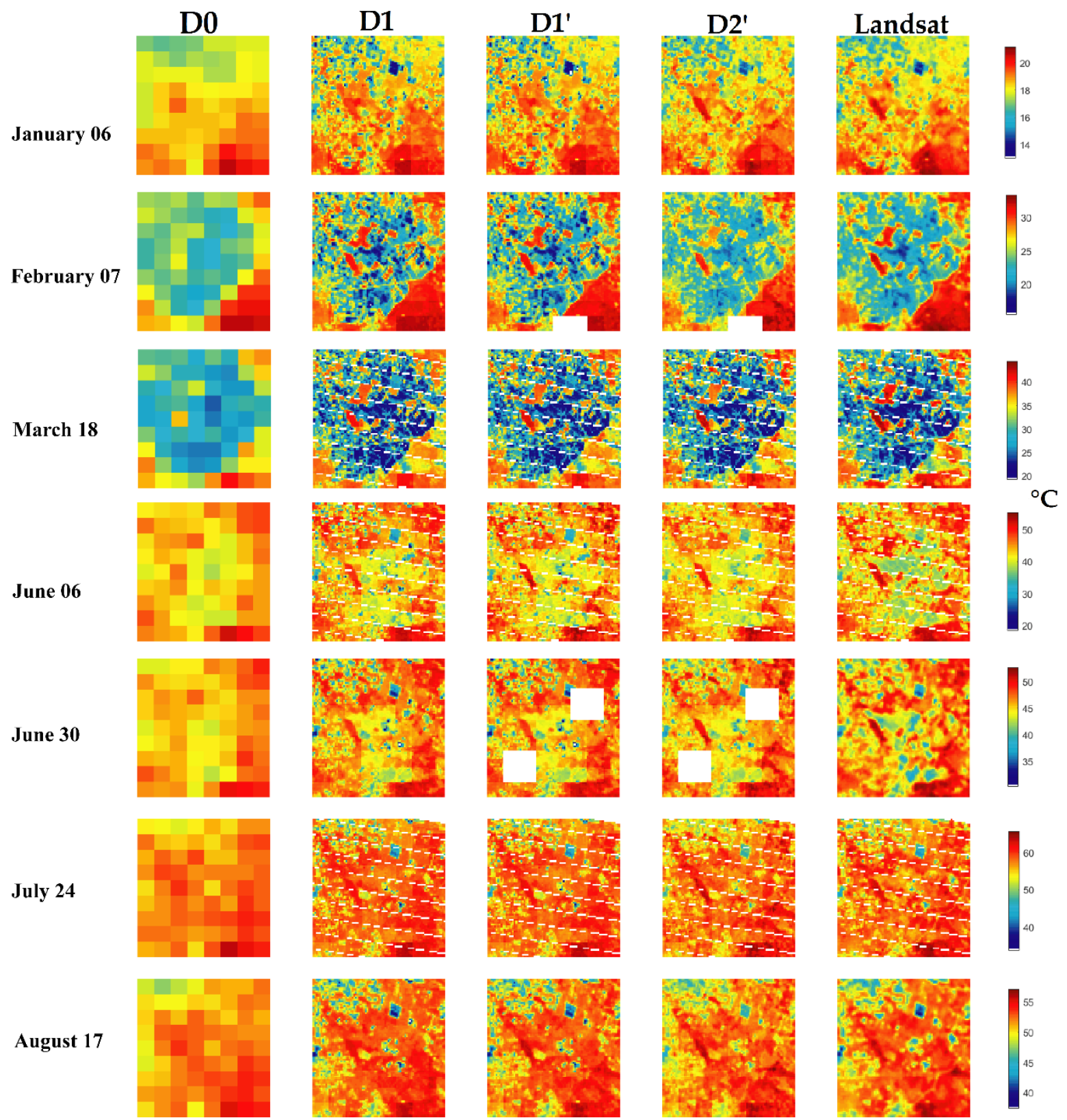

405

406

407

408

409

410

411

Fig.8. Maps of the LR (Landsat-aggregated) LST disaggregated by the four algorithms compared to the Landsat reference HR LST on the seven selected dates separately over R3 area. The data gaps on February 07 and June 30 for D1' and D2' are attributed to S-1 raw data (no data value).

To facilitate the comparison between the algorithms, they are plotted against the Landsatderived temperature over the R3 site in Fig.9. The statistical results for each algorithm are summarized in Table 4. 


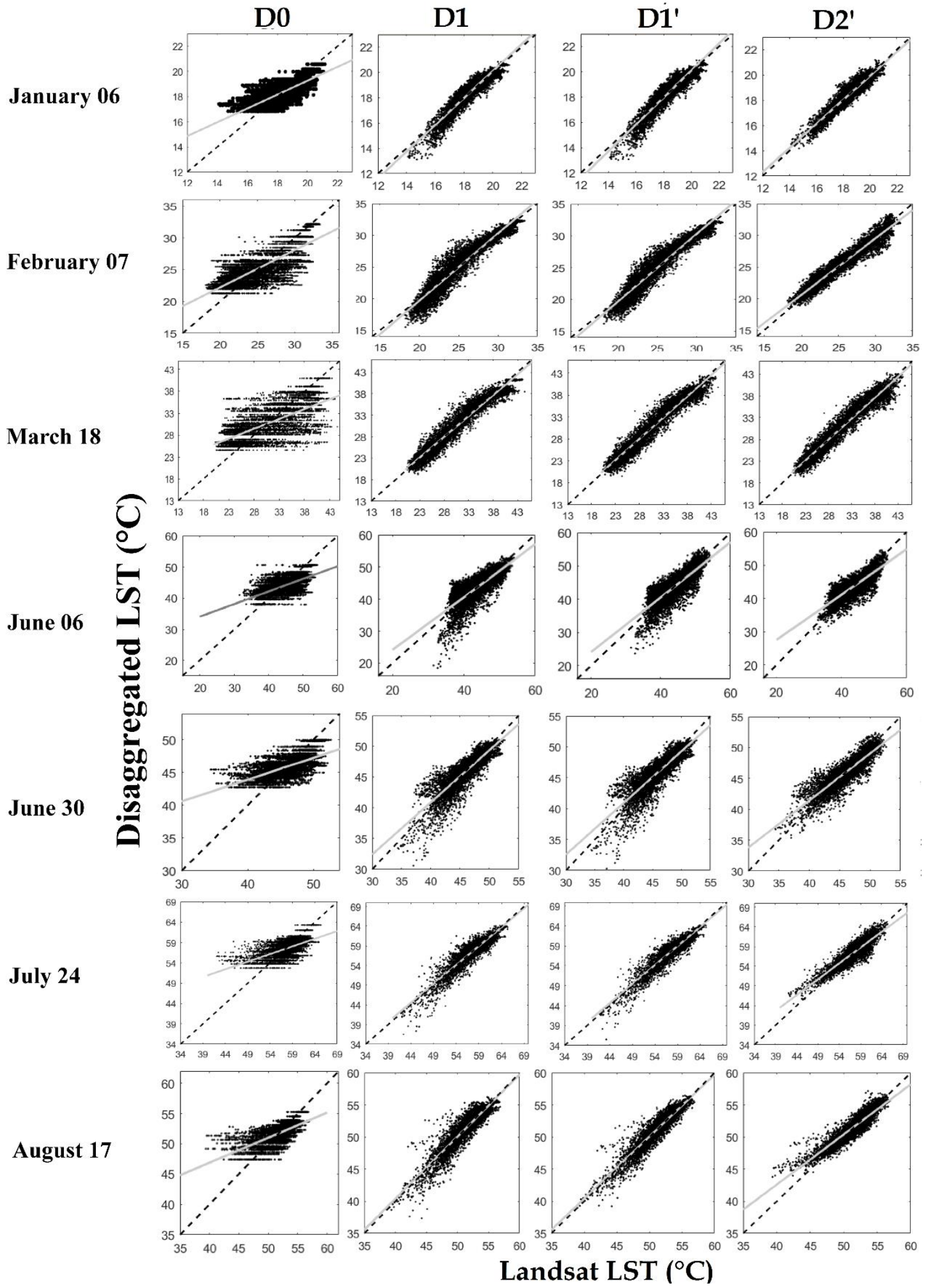

Fig. 9. Comparison between the LST disaggregated using each algorithm against the HR Landsat LST for the seven dates over $R 3$ area.

415 Table 4: Summary statistics of the disaggregation algorithms. For D2', LST endmembers are derived 416 from the contextual spaces defined by HR ancillary data.
Date
R (-)
RMSE $\left({ }^{\circ} \mathrm{C}\right)$
Slope (-) 


\begin{tabular}{l|cccccccccccc} 
& D0 & D1 & D1 & D2 & D0 & D1 & D1' & D2, & D0 & D1 & D1' & D2' \\
January 06 & 0.76 & 0.93 & 0.93 & 0.94 & 0.71 & 0.45 & 0.47 & 0.36 & 0.55 & 1.06 & 1.06 & 0.95 \\
February 07 & 0.78 & 0.95 & 0.96 & 0.97 & 2.26 & 1.26 & 1.15 & 0.91 & 0.59 & 1.06 & 1.06 & 0.89 \\
March 18 & 0.66 & 0.97 & 0.97 & 0.97 & 4.42 & 1.48 & 1.44 & 1.46 & 0.45 & 0.96 & 0.97 & 0.96 \\
June 06 & 0.63 & 0.80 & 0.82 & 0.83 & 3.31 & 2.78 & 2.61 & 2.37 & 0.40 & 0.82 & 0.82 & 0.68 \\
June 30 & 0.61 & 0.86 & 0.86 & 0.88 & 2.25 & 1.47 & 1.54 & 1.39 & 0.33 & 0.84 & 0.84 & 0.76 \\
July 24 & 0.61 & 0.91 & 0.92 & 0.90 & 2.54 & 1.37 & 1.27 & 1.40 & 0.37 & 0.96 & 0.95 & 0.80 \\
August 17 & 0.67 & 0.92 & 0.94 & 0.92 & 1.81 & 1.01 & 0.87 & 0.97 & 0.41 & 0.96 & 0.96 & 0.78 \\
All & 0.67 & 0.90 & 0.91 & 0.91 & 2.47 & 1.40 & 1.33 & 1.26 & 0.44 & 0.95 & 0.95 & 0.83
\end{tabular}

417

418

419

420

421

422

423

424

425

426

427

428

429

430

431

432

433

434

435

436

437

438

439

440

441

442

Data points in the scatterplot of the new (D2') algorithm fall closer to the 1:1 line. Based on Table 4, D1, D1' and D2' generate better results than D0. The improved disaggregation algorithms show a decrease in the root mean square error (RMSE) with $1.26,1.15$ and $0.91{ }^{\circ} \mathrm{C}$ using the D1, D1' and D2' algorithms, respectively compared to D0, which shows an error up to $2.2^{\circ} \mathrm{C}$ on 07 February as an example.

The results change from date to date, but in general in our study case we found that, the MLR D1' and RTM D2' algorithms provide better results in term of correlation coefficient (R) and RMSE than the original approach D1. A better slope of the linear regression between disaggregated and Landsat LST is provided by D1 and D1' whereas D2' degrades slightly the slope on the same dates. The good results provided by the D1' algorithm are attributed to an efficient calibration at LR of the coefficients of the regression fit between LST, $f_{\mathrm{gv}}$ and the radar backscatter. Moreover, the RTM model is sensitive to uncertainties in extreme LST, which in this case, were derived using HR Landsat data. The Landsat-derived temperature endmembers may be significantly biased in the case where/when surface conditions are relatively homogeneous (in particular over rainfed sites like Sidi Rahal).

The mean R between disaggregated and Landsat LST slightly increases from 0.90 to 0.91 , and the mean RMSE decreases from $1.40{ }^{\circ} \mathrm{C}$ to $1.26{ }^{\circ} \mathrm{C}$ using the D1 and D2' algorithms, respectively. In contrast, the mean slope is decreased from 0.95 to 0.83 using D1 and D2' algorithms, respectively.

Since HR Landsat LST is assumed to be unavailable in our disaggregation exercise, the LST endmembers are now derived from LR LST data only (instead of using HR LST data as previously). Table 5 lists the RMSE, R, and slope of the linear regression between disaggregated and Landsat LST for D2' algorithm, using the temperature endmembers derived from LR LST data combined with EB model estimates.

Table 5: Statistics of the disaggregation algorithms using temperature endmembers estimated by EB modelling (estimated by $L S T-f_{g v}$ spaces defined using HR data in parenthesis). 


\begin{tabular}{c|ccc} 
Date & R $(-)$ & RMSE $\left({ }^{\circ} \mathbf{C}\right)$ & Slope \\
\hline January 06 & $0.87(0.94)$ & $0.85(0.36)$ & $1.27(0.95)$ \\
February 07 & $0.97(0.97)$ & $0.89(0.91)$ & $0.92(0.89)$ \\
March 18 & $0.96(0.97)$ & $1.60(1.46)$ & $0.88(0.96)$ \\
June 06 & $0.83(0.83)$ & $2.40(2.37)$ & $0.66(0.68)$ \\
June 30 & $0.87(0.88)$ & $1.43(1.39)$ & $0.73(0.76)$ \\
July 24 & $0.86(0.90)$ & $1.65(1.40)$ & $0.79(0.80)$ \\
August 17 & $0.87(0.92)$ & $1.21(0.97)$ & $0.80(0.78)$ \\
All & $0.89(0.91)$ & $1.43(1.26)$ & $0.86(0.83)$
\end{tabular}

A valuable discussion is presented in this paragraph that helps to see the impact of the LST endmembers estimation on the disaggregation results. Looking at the Table 5, the statistical results clearly show that the disaggregated LST is more accurate when using the LST endmembers derived from Landsat HR data than those derived from EB modelling (combined with LR data). In contrast, using EB-derived extreme LST provides a slightly better mean slope (0.86) than when using HR data (0.83). In order to assess the main causes behind that, the $\mathrm{T}_{\mathrm{bs}, \mathrm{d}}$ estimated by the EB model is compared to the maximum value observed at HR. On January 06 , an overestimation of about $8{ }^{\circ} \mathrm{C}$ of $\mathrm{T}_{\mathrm{bs}, \mathrm{d}}$ is observed when using the EB model (data not shown here), which leads to slightly poorer results compared to when using temperature endmembers derived from HR spaces. It is suggested that the temperature endmembers derived from EB modeling are more uncertain than those derived from HR spaces, especially over a highly heterogeneous area like R3.

\subsection{Application to MODIS data}

In this section, the disaggregation methodologies D0, D1, D1' and D2' are applied to MODIS/Terra (MOD11-A1) LST product over only the R3 site. It is reminded that only the MODIS images acquired on the same dates as Landsat data are used for the evaluation. For the rainfed Sidi Rahal site, the MODIS LST data are affected by clouds where the contaminated pixel are masked with the MODIS cloud mask data product. Therefore no MODIS image is clear, which limits the application to MODIS data over this site. Fig.10 compares the disaggregation images with the $100 \mathrm{~m}$ resolution Landsat LST for six selected dates. Note that the MODIS image on August 17 is affected by clouds and was thus removed. In the implementation of D2', the temperature endmembers are estimated using EB modelling. 

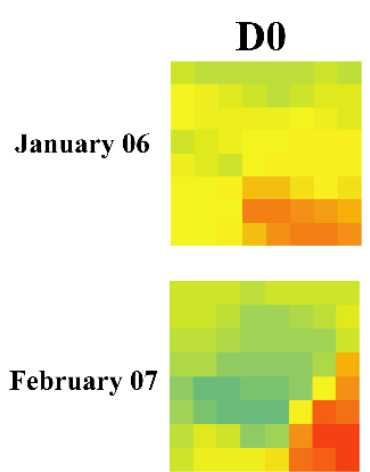

July 24

466

467

468
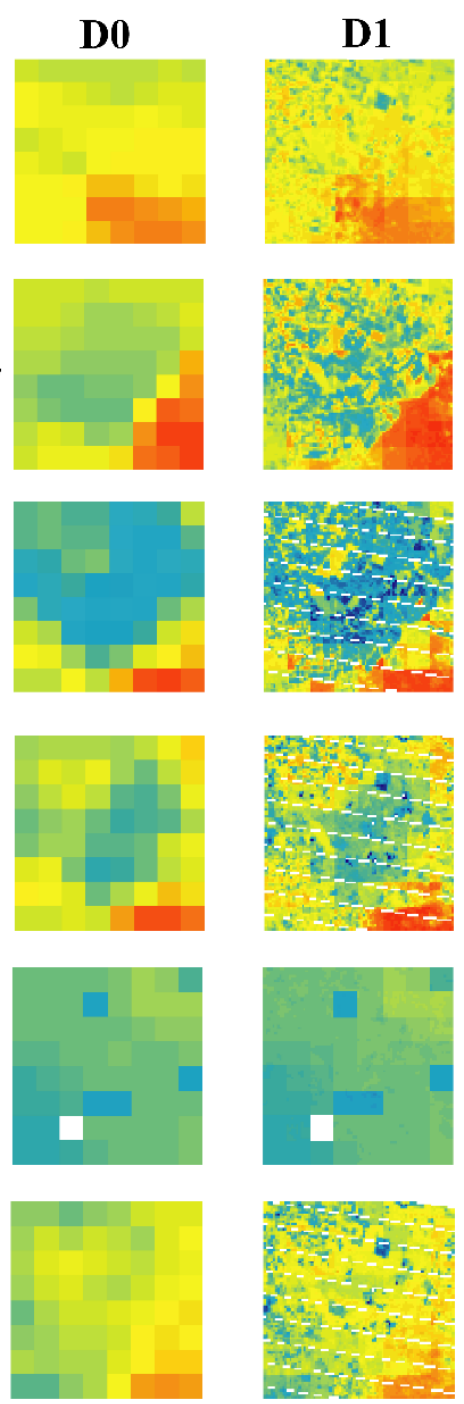
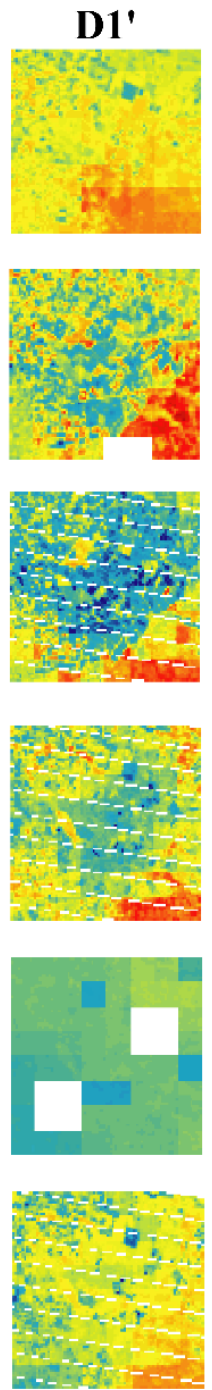
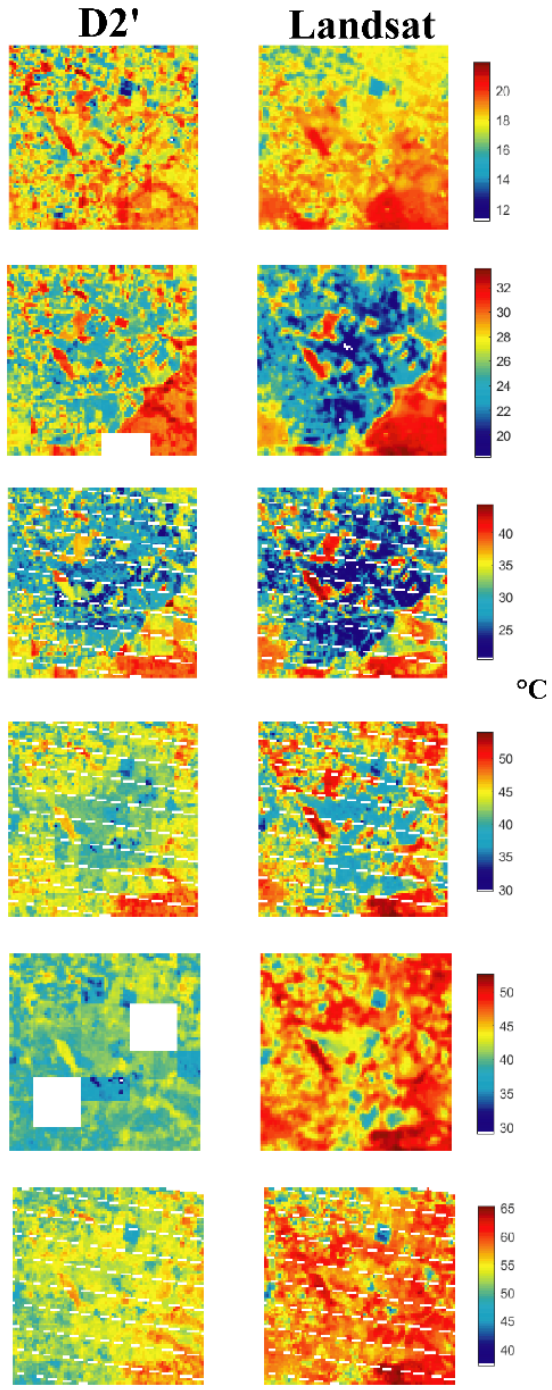

Fig.10. Maps of the MODIS LST disaggregated at HR by the four algorithms compared to the Landsat reference LST map on the six clear sky dates over $R 3$ area. 

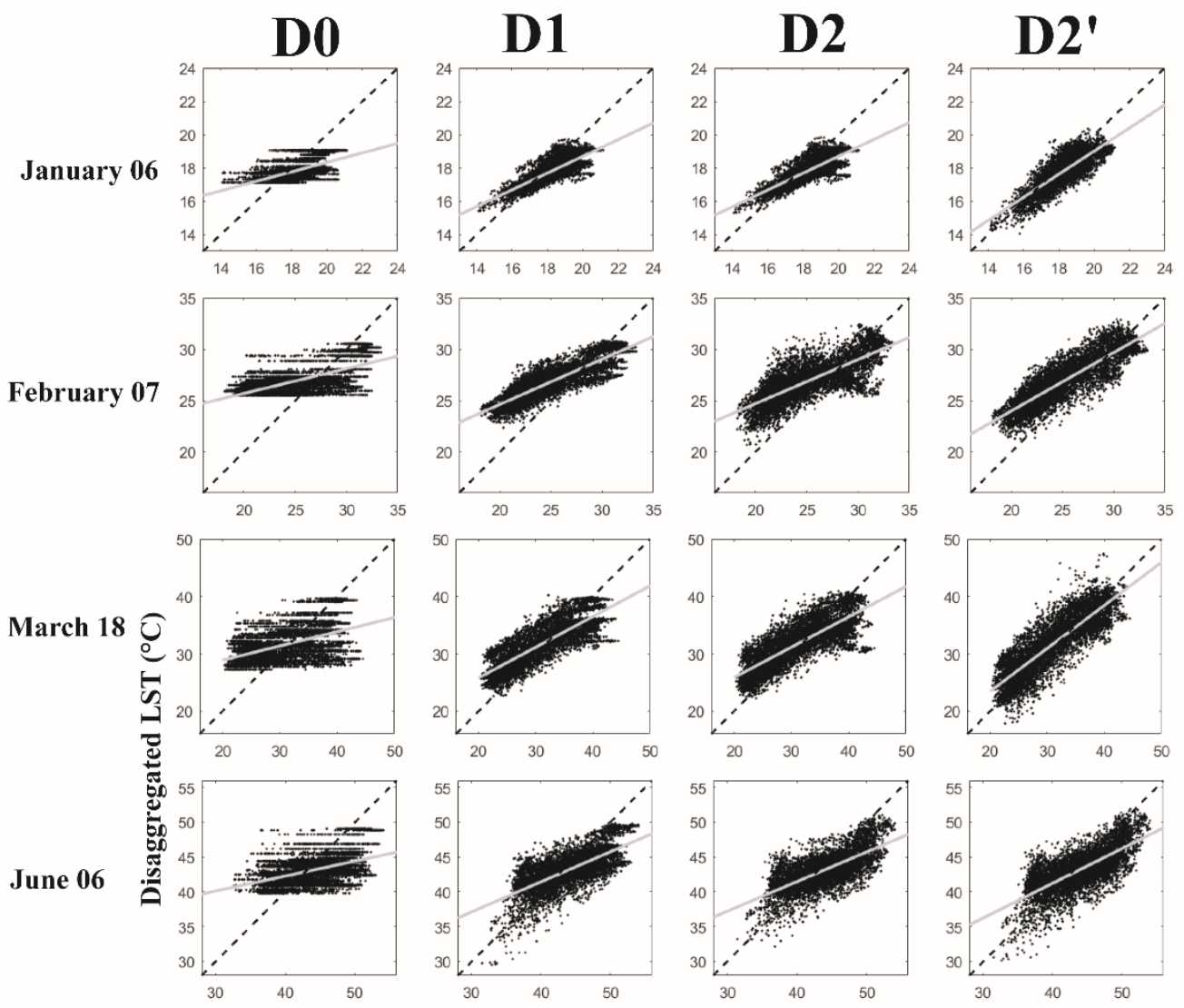

June 30
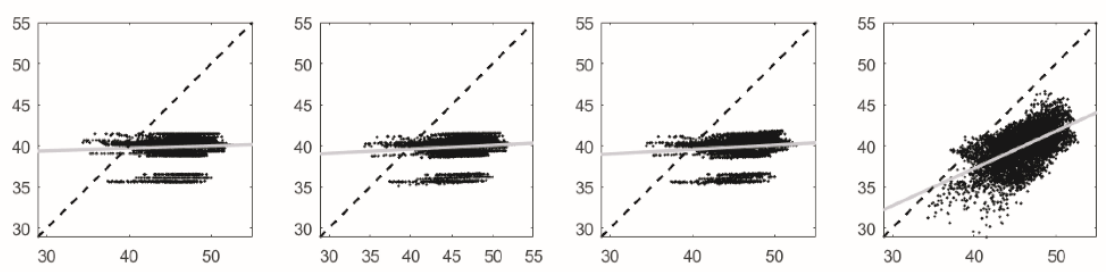

July 24
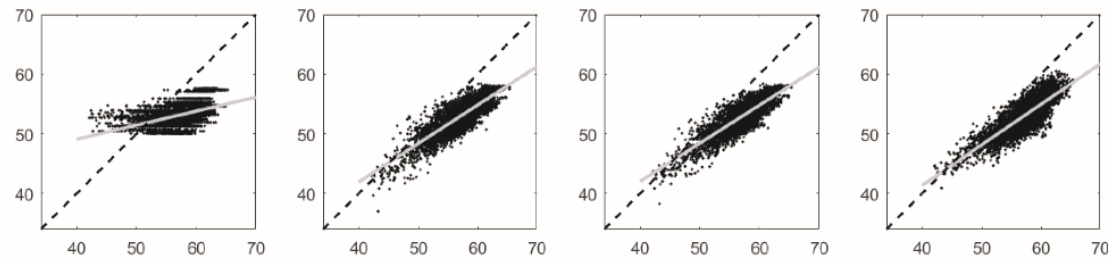

Landsat LST $\left({ }^{\circ} \mathrm{C}\right)$

Fig.11. Comparison between the disaggregated LST using each algorithm against the HR Landsat

472 Table 6: Summary statistics of the disaggregation algorithms. Temperature endmembers are estimated

473 from EB modelling.

\begin{tabular}{|c|c|c|c|c|c|c|c|c|c|c|c|c|}
\hline \multirow{2}{*}{ Date } & \multicolumn{4}{|c|}{$R(-)$} & \multicolumn{4}{|c|}{$\operatorname{RMSE}\left({ }^{\circ} \mathrm{C}\right)$} & \multicolumn{4}{|c|}{ Slope } \\
\hline & D0 & D1 & D1' & D2' & D0 & D1 & D1' & D2' & D0 & D1 & D1' & D2' \\
\hline January 06 & 0.56 & 0.80 & 0.80 & 0.75 & 1.03 & 0.83 & 0.83 & 1.09 & 0.28 & 0.50 & 0.50 & 1.01 \\
\hline February 07 & 0.65 & 0.87 & 0.76 & 0.86 & 3.34 & 2.73 & 2.94 & 2.57 & 0.24 & 0.44 & 0.43 & 0.59 \\
\hline March 18 & 0.51 & 0.83 & 0.80 & 0.86 & 5.16 & 3.57 & 3.71 & 2.20 & 0.24 & 0.53 & 0.53 & 0.65 \\
\hline June 06 & 0.47 & 0.70 & 0.71 & 0.71 & 3.84 & 3.16 & 3.14 & 3.09 & 0.21 & 0.43 & 0.42 & 0.44 \\
\hline
\end{tabular}




\begin{tabular}{|c|c|c|c|c|c|c|c|c|c|c|c|c|}
\hline June 30 & $\mathbf{0 . 0 7}$ & $\mathbf{0 . 1 2}$ & $\mathbf{0 . 1 3}$ & $\mathbf{0 . 5 5}$ & $\mathbf{6 . 7 1}$ & $\mathbf{6 . 6 8}$ & $\mathbf{6 . 7 1}$ & $\mathbf{6 . 4 4}$ & $\mathbf{0 . 0 3}$ & $\mathbf{0 . 0 5}$ & $\mathbf{0 . 0 5}$ & $\mathbf{0 . 3 8}$ \\
\hline July 24 & $\mathbf{0 . 4 7}$ & $\mathbf{0 . 8 4}$ & $\mathbf{0 . 8 4}$ & $\mathbf{0 . 7 8}$ & $\mathbf{5 . 1 4}$ & $\mathbf{4 . 6 4}$ & $\mathbf{4 . 6 4}$ & $\mathbf{4 . 7 1}$ & $\mathbf{0 . 2 3}$ & $\mathbf{0 . 6 4}$ & $\mathbf{0 . 6 4}$ & $\mathbf{0 . 5 8}$ \\
\hline All & $\mathbf{0 . 4 5}$ & $\mathbf{0 . 6 9}$ & $\mathbf{0 . 6 7}$ & $\mathbf{0 . 7 5}$ & $\mathbf{4 . 2 0}$ & $\mathbf{3 . 6 0}$ & $\mathbf{3 . 6 6}$ & $\mathbf{3 . 3 5}$ & $\mathbf{0 . 2 0}$ & $\mathbf{0 . 4 3}$ & $\mathbf{0 . 4 3}$ & $\mathbf{0 . 6 1}$ \\
\hline
\end{tabular}

474

475

476

477

478

479

480

481

482

483

484

485

486

487

488

489

490

491

492

493

494

495

496

497

498

499

500

501

502

Looking at the spatial patterns of disaggregated LST maps, the values in all maps range from $14{ }^{\circ} \mathrm{C}$ to $60{ }^{\circ} \mathrm{C}$. The boxy effect anomalies are less apparent for D2' algorithm compared to the original algorithms. Generally, the disaggregation algorithms of MODIS LST show a lower maximum and higher minimum than Landsat LST.

The downscaling results and statistics are shown in Fig. 11 and reported in Table 6. The D2' algorithm provides better results than the MLR approaches (D1 and D1'). Results in Table 6 shows that the minimum mean RMSE is $3.35^{\circ} \mathrm{C}$ and the highest mean $\mathrm{R}$ is 0.75 , which are both obtained with D2' algorithm. A systematic negative bias is apparent in the disaggregated temperature using MODIS LST, quite consistent with the mean bias between MODIS and Landsat LST estimated as $4{ }^{\circ} \mathrm{C}$ in this work. As expected the disaggregation method does not yield similar results when applied to MODIS/Terra LST instead of aggregated Landsat data. This is due to the discrepancy between MODIS and Landsat data, and to different sensitivities of MLR and RTM algorithms to uncertainties (including bias) in LR input data. However, in our study case over the selected irrigated perimeter, the new algorithm D2' clearly improves the disaggregated LST against the classical approaches. When comparing the new algorithm D2' to the classical one D1, D2' generally shows the best results with an increase of R from 0.83 to 0.86 and a decrease in the RMSE from 3.57 to $2.20{ }^{\circ} \mathrm{C}$, respectively (18 March as an example). By comparing the performance of the disaggregation algorithms using aggregated Landsat and real MODIS LST, the aggregated Landsat LST provides better results than MODIS LST. The reason is due to the fact that real images have an additional noise in the LST data which may be related to sensor registration (Essa et al., 2013). In addition, part of the error could be attributed to differences in the algorithms used to retrieve LST, which are not the same (split-window for MODIS and single-channel for Landsat). A relatively poor performance is observed for D1 and D1' on 30 June compared to the new D2' methodology. On that date MODIS LST largely underestimates Landsat LST. However, D2' provides a much better $\mathrm{R}$ ( 0.55 instead of 0.1 for all the other approaches). We argue that the RTM method (D2'), is more accurate and more robust than MLR method (D1') especially when applying it to real data (MODIS LST). In particular, it is much less sensitive to uncertainties in LR LST than MLR method. Based on the acquired results, RTM algorithm performed 
503

504

505

506

507

508

509

510

511

512

513

514

515

516

517

518

519

520

521

522

523

524

525

526

527

528

529

530

531

532

better than the classical algorithm and in most cases than the RTM method where it stabilizes the errors and systematically increases the R between disaggregated and Landsat LST.

\section{Conclusion}

The objective of this paper is to disaggregate MODIS/Terra LST data to $100 \mathrm{~m}$ resolution over an irrigated semi-arid area. The idea is to include the high spatial resolution soil moisture variability in the disaggregation algorithm, in addition to the classical fraction of green vegetation cover. The approaches are tested over two heterogonous sites: $8 \mathrm{~km}$ by $8 \mathrm{~km}$ irrigated perimeter and a $12 \mathrm{~km}$ by $12 \mathrm{~km}$ rainfed area south of Marrakech during the 20152016 growing season. The algorithms are firstly tested using the $1 \mathrm{~km}$ aggregated Landsat-7/8 surface temperature as input to avoid the errors and random uncertainty produced by the registration of LR sensors like MODIS. Then, the performance of the used algorithms is assessed using MODIS/Terra daytime LST as input. The Landsat LST at $100 \mathrm{~m}$ resolution is mainly used for validation purposes.

Best results are obtained with the new algorithm denoted D2' when using MODIS LST data based on the RTM equation, compared to the procedure based on a linear regression between $\mathrm{f}_{\mathrm{gv}}$ and LST, and also compared to the multi-linear regression between $\mathrm{f}_{\mathrm{gv}}, \sigma_{\mathrm{vv}}^{0}$ and LST. Since the selected area showed a heterogeneity in terms of vegetation type and soil water status, we conclude that the new algorithm produces more stable and robust results during the selected year. $0.83{ }^{\circ} \mathrm{C}$ and 0.86 were the lowest RMSE and the highest correlation coefficient assessed using the new algorithm. These results are encouraging and can be used to reinforce and to improve the application of downscaling procedure to low resolution thermal sensors. Sentinel2 (S-2) is a continuity of Landsat reflectances with an improvement in the spatio-temporal resolution. Therefore, the application of the disaggregation algorithm to MODIS LST using S2 ancillary data will improve the temporal resolution to 5 days. This work also can be considered as a basis for new missions dedicated to provide TIR data at high spatio-temporal resolution (India-France joint satellite mission, Trishna). Further research must be undertaken to incorporate the vegetation water stress into the disaggregation methods, possibly by integrating the S-1 VH polarization data, which are more sensitive to vegetation water content effects than VV polarization.

\section{Appendix}


533 To run EB model, the soil temperature is set to air temperature ( $\left.\mathrm{T}_{\text {air }}\right)$ and an iterative loop on 534 the soil temperature is made until the thermal equilibrium is reached by minimizing the cost 535 function (F(LST)) by finding the LST value corresponding to the EB closure:

$$
\mathrm{F}(\mathrm{LST})=\left(\mathrm{R}_{\mathrm{n}}-\mathrm{G}-\mathrm{H}-\mathrm{LE}\right)^{2}
$$

537 Starting from the EB model equation, where the available energy is set equal to the turbulent 538 fluxes:

$$
\mathrm{R}_{\mathrm{n}}-\mathrm{G}=\mathrm{LE}+\mathrm{H}
$$

549 with

where $\varepsilon_{\mathrm{a}}$ is the atmospheric emissivity (Brutsaert, 1975):

550 551

552

553

554

555

$$
\mathrm{R}_{\mathrm{atm}}=\varepsilon_{\mathrm{a}} \times \sigma \mathrm{T}_{\mathrm{air}}^{4}
$$

$$
\varepsilon_{\mathrm{a}}=1.24 \times\left(\frac{\mathrm{e}_{\mathrm{a}}}{\mathrm{T}_{\mathrm{air}}}\right)^{\frac{1}{7}}
$$

$$
\mathrm{e}_{\mathrm{a}}=\mathrm{e}_{\mathrm{s}}\left(\mathrm{T}_{\mathrm{air}}\right) \times \frac{\mathrm{rh}_{\mathrm{a}}}{100}
$$

$\mathrm{rh}_{\mathrm{a}}(\%)$ being the air relative humidity and $\mathrm{e}_{\mathrm{s}}$ the saturated water vapour pressure $(\mathrm{kPa})$ given by:

$$
e_{s}=0.611 \times e^{\left(\frac{17.27 \times T_{a i r}}{T_{\text {air }}+273.3}\right)}
$$

The ground flux $G$ is estimated as a fraction of net radiation at the surface $R_{n}$ :

$$
\mathrm{G}=\operatorname{cg} \cdot \mathrm{R}_{\mathrm{n}}
$$

with cg being a fractional empirical coefficient set to 0.2 .

The sensible heat flux is given by:

The latent heat flux is estimated as:

$$
\mathrm{H}=\rho c_{\mathrm{p}} \frac{\mathrm{T}_{\mathrm{s}}-\mathrm{T}_{\mathrm{air}}}{\mathrm{r}_{\mathrm{a}, \mathrm{h}}}
$$




$$
\mathrm{LE}=\frac{\rho c_{\mathrm{p}}}{\gamma} \frac{\mathrm{e}_{\mathrm{s}}-\mathrm{e}_{\mathrm{a}}}{\mathrm{r}_{\mathrm{a}, \mathrm{h}}+\mathrm{r}_{\mathrm{ss}}}
$$

560

561

562

563

564

565

566

567

568

569

570

571

\section{Acknowledgements}

This study was conducted within both the International Joint Laboratory-TREMA-Morocco (http://trema.ucam.ac.ma/) and the Centre for the study of the biosphere from space-France (http://www.cesbio.ups-tlse.fr/) and received funding from the European Commission Horizon 2020 Programme for Research and Innovation (H2020) in the context of the Marie Sklodowska-Curie Research and Innovation Staff Exchange (RISE) action (REC project, grant agreement no: 645642) http://rec.isardsat.com/. The MIXMOD-E project (ANR-13JS06-0003-01) funded by the French Agence Nationale de la Recherche is acknowledged. The Moroccan CNRST (Centre National pour la Recherche Scientifique et Technique) (https://www.cnrst.ma/) is also acknowledged for awarding a $\mathrm{PhD}$ scholarship to Abdelhakim Amazirh.

\section{Glossary}

\begin{tabular}{|c|c|}
\hline Symbols & signification and unit \\
\hline $\mathbf{P}_{\sigma_{\mathrm{Vy}}^{\mathbf{0}}}$ & Soil moisture proxy \\
\hline$\sigma_{\mathrm{vv}, \max }^{0}$ & Backscatter coefficient correspond to the wettest pixel during the season \\
\hline$\sigma_{\mathrm{vv}, \min }^{0}$ & Backscatter coefficient correspond to the driest pixel during the season \\
\hline$\sigma_{\mathrm{vv}, \mathbf{g v}}^{\mathbf{0}}$ & Green vegetation backscatter coefficient \\
\hline$\sigma_{\mathrm{vv}, \mathrm{bs}, \mathbf{d}}^{\mathbf{0}}$ & Bare dry soil backscatter coefficient \\
\hline$\sigma_{\mathrm{vv}, \mathrm{bs}, \mathrm{w}}^{\mathbf{0}}$ & Bare wet soil backscatter coefficient \\
\hline $\mathbf{T}_{\mathrm{fc}, \mathrm{gv}}$ & The temperature of pixel with fully-covered vegetation \\
\hline $\mathbf{T}_{\mathbf{b s}}^{\mathbf{S m}}$ & Ttemperature estimated using a linearized RTM \\
\hline $\mathbf{T}_{\mathrm{bs}, \mathrm{w}}$ & Wet bare soil temperature \\
\hline $\mathbf{T}_{\text {bs,d }}$ & Dry bare soil temperature \\
\hline$\sigma_{\mathrm{vv}}^{0}$ & VV polarized backscatter coefficient \\
\hline$\sigma_{\mathrm{vv}, \mathrm{km}}^{\mathbf{0}}$ & Aggregated VV polarized backscatter coefficient \\
\hline$\Delta \mathbf{T}_{2}^{\prime}$ & Corrective term \\
\hline $\mathrm{r}_{\mathrm{ss}}$ & Evaporation surface resistance, $\mathrm{s} \mathrm{m}^{-1}$ \\
\hline $\mathrm{R}_{\mathrm{n}}$ & Net radiation, $\mathrm{W} \mathrm{m}^{-2}$ \\
\hline $\mathrm{G}$ & Soil heat flux, $\mathrm{W} \mathrm{m}^{-2}$ \\
\hline $\mathrm{H}$ & Sensible heat flux, $\mathrm{W} \mathrm{m}^{-2}$ \\
\hline LE & Latent heat flux, $\mathrm{W} \mathrm{m}^{-2}$ \\
\hline ua & Wind speed, $\mathrm{m} \mathrm{s}^{-1}$ \\
\hline$r_{g}$ & Solar radiation, $\mathrm{W} \mathrm{m}^{-2}$ \\
\hline $\mathrm{rh}_{\mathrm{a}}$ & Relative humidity, $\%$ \\
\hline $\mathrm{T}_{\text {air }}$ & Air temperature, ${ }^{\circ} \mathrm{C}$ \\
\hline$\varepsilon$ & Surface emissivity \\
\hline
\end{tabular}




\begin{tabular}{|l|l|}
\hline$\gamma$ & Psychrometric constant, $\mathrm{kPa}{ }^{\circ} \mathrm{C}^{-1}$ \\
\hline$\rho$ & Mean air density at constant pressure, $\mathrm{kg} \mathrm{m}^{-3}$ \\
\hline$c_{\mathrm{p}}$ & Stands for the specific heat of air, $\mathrm{MJ} \mathrm{kg}^{-1}{ }^{\circ} \mathrm{C}^{-1}$ \\
\hline $\mathrm{e}_{\mathrm{a}}$ & Actual vapour pressure, $\mathrm{kPa}$ \\
\hline $\mathrm{e}_{\mathrm{s}}$ & Saturation vapour pressure, $\mathrm{kPa}$ \\
\hline $\mathrm{r}_{\mathrm{a}, \mathrm{h}}$ & Aerodynamic resistance, $\mathrm{s} \mathrm{m}^{-1}$ \\
\hline$\alpha$ & Surface albedo \\
\hline $\mathrm{R}_{\mathrm{atm}}$ & Atmospheric longwave radiation, $\mathrm{W} \mathrm{\textrm {m } ^ { - 2 }}$ \\
\hline$\sigma$ & Stephan-Boltzmann constant equal to $5.67 \times 10^{-8}, \mathrm{~W} \mathrm{~m}^{-2} \mathrm{~K}^{-4}$ \\
\hline$\varepsilon_{\mathrm{a}}$ & Atmospheric emissivity \\
\hline$c_{\mathrm{g}}$ & Fractional empirical coefficient set to 0.2 \\
\hline$f_{\mathrm{gv}}$ & Fraction of green vegetation cover \\
\hline $\mathbf{f}_{\mathbf{g v}, \mathbf{k m}}$ & Aggregated fraction of green vegetation cover \\
\hline $\mathrm{NDVI}$ & Full-cover green vegetation index \\
\hline NDVI & Bare soil vegetation index \\
\hline F (LST) & Cost function \\
\hline
\end{tabular}

\section{References}

Agam, N., Kustas, W.P., Anderson, M.C., Li, F., Colaizzi, P.D., 2007a. Utility of thermal sharpening over Texas high plains irrigated agricultural fields. Journal of Geophysical Research Atmospheres 112, 1-10. doi:10.1029/2007JD008407

Agam, N., Kustas, W.P., Anderson, M.C., Li, F., Neale, C.M.U., 2007b. A vegetation index based technique for spatial sharpening of thermal imagery. Remote Sensing of Environment 107, 545-558. doi:10.1016/j.rse.2006.10.006

Amazirh, A., Er-Raki, S., Chehbouni, A., Rivalland, V., Diarra, A., Khabba, S., Ezzahar, J., Merlin, O., 2017. Modified Penman-Monteith equation for monitoring evapotranspiration of wheat crop: Relationship between the surface resistance and remotely sensed stress index. Biosystems Engineering 164, 68-84. doi:10.1016/j.biosystemseng.2017.09.015

Amazirh, A., Merlin, O., Er-raki, S., Gao, Q., Rivalland, V., Malbeteau, Y., Khabba, S., José, M., 2018. Retrieving surface soil moisture at high spatio-temporal resolution from a synergy between Sentinel-1 radar and Landsat thermal data: A study case over bare soil. Remote Sensing of Environment 211, 321-337. doi:10.1016/j.rse.2018.04.013

Anderson, M.C., Norman, J.M., Kustas, W.P., Houborg, R., Starks, P.J., Agam, N., 2008. A thermal-based remote sensing technique for routine mapping of land-surface carbon, water and energy fluxes from field to regional scales. Remote Sensing of Environment 112, 4227-4241. doi:10.1016/j.rse.2008.07.009

Bastiaanssen, W.G.M., Menenti, M., Feddes, R.A., Holtslag, A.A.M., 1998. A remote sensing surface energy balance algorithm for land (SEBAL). Journal of Hydrology. doi:10.1016/S0022-1694(98)00253-4

Bindhu, V.M., Narasimhan, B., Sudheer, K.P., 2013. Development and verification of a nonlinear disaggregation method (NL-DisTrad) to downscale MODIS land surface temperature to the spatial scale of Landsat thermal data to estimate evapotranspiration. Remote Sensing of Environment 135, 118-129. doi:10.1016/j.rse.2013.03.023

Boulet, G., Chehbouni, A., Gentine, P., Duchemin, B., Ezzahar, J., Hadria, R., 2007. Monitoring water stress using time series of observed to unstressed surface temperature difference. Agricultural and Forest Meteorology 146, 159-172. doi:10.1016/j.agrformet.2007.05.012

Brunsell, N.A., Gillies, R.R., 2003. Length Scale Analysis of Surface Energy Fluxes Derived 
from Remote Sensing. Journal of Hydrometeorology 4, 1212-1219. doi:10.1175/15257541(2003)004<1212:1saose>2.0.co;2

Brutsaert, W., 1975. On a derivable formula for long-wave radiation from clear skies. Water Resources Research 4, 742-744. doi:10.1029/WR011i005p00742

Chehbouni, A.H., Escadafal, R., Duchemin, B., Boulet, G., Simonneaux, V., Dedieu, G., Mougenot, B., Khabba, S., Kharrou, H., Maisongrande, P., Merlin, O., Chaponnière, A., Ezzahar, J., Er-Raki, S., Hoedjes, J., Hadria, R., Abourida, A., Cheggour, A., Raibi, F., Boudhar, A., Benhadj, I., Hanich, L., Benkaddour, A., Guemouria, N., Chehbouni, A.H., Lahrouni, A., Olioso, A., Jacob, F., Williams, D.G., Sobrino, J.A., 2008. An integrated modelling and remote sensing approach for hydrological study in arid and semi-arid regions: the SUDMED Programme. International Journal of Remote Sensing 29, 51615181. doi:10.1080/01431160802036417

Chen, L., Yan, G.J., Ren, H.Z., Li, A.H., Ieee, 2010. a Modified Vegetation Index Based Algorithm for Thermal Imagery Sharpening. 2010 Ieee International Geoscience and Remote Sensing Symposium. doi:10.1109/igarss.2010.5651428

Crow, W.T., Wood, E.F., 2003. The assimilation of remotely sensed soil brightness temperature imagery into a land surface model using Ensemble Kalman filtering: A case study based on ESTAR measurements during SGP97. Advances in Water Resources 26, 137-149. doi:10.1016/S0309-1708(02)00088-X

Dominguez, A., Kleissl, J., Luvall, J.C., Rickman, D.L., 2011. High-resolution urban thermal sharpener (HUTS). Remote Sensing of Environment 115, 1772-1780. doi:10.1016/j.rse.2011.03.008

Duchemin, B., Hagolle, O., Mougenot, B., Benhadj, I., Hadria, R., Simonneaux, V., Ezzahar, J., Hoedjes, J., Khabba, S., Kharrou, M.H., Boulet, G., Dedieu, G., Er-Raki, S., Escadafal, R., Olioso, A., Chehbouni, A.G., 2008. Agrometerological study of semi-arid areas: an experiment for analysing the potential of time series of FORMOSAT-2 images (Tensift-Marrakech plain). International Journal of Remote Sensing 29, 5291-5299. doi:10.1080/01431160802036482

Er-Raki, S., Amazirh, A., Ayyoub, A., Khabba, S., Merlin, O., Ezzahar, J., Chehbouni, A., 2018. Integrating thermal surface temperature into Penman-Monteith model for estimating evapotranspiration and crop water stress of orange orchard in semi-arid region, Acta Horticulturae. doi:10.17660/ActaHortic.2018.1197.12

Er-Raki, S., Chehbouni, A., Boulet, G., Williams, D.G., 2010. Using the dual approach of FAO-56 for partitioning ET into soil and plant components for olive orchards in a semiarid region. Agricultural Water Management 97, 1769-1778. doi:10.1016/j.agwat.2010.06.009

Er-Raki, S., Chehbouni, A., Guemouria, N., Duchemin, B., Ezzahar, J., Hadria, R., 2007. Combining FAO-56 model and ground-based remote sensing to estimate water consumptions of wheat crops in a semi-arid region. Agricultural Water Management 87, 41-54. doi:10.1016/j.agwat.2006.02.004

Ghosh, A., Joshi, P.K., 2014. ISPRS Journal of Photogrammetry and Remote Sensing Hyperspectral imagery for disaggregation of land surface temperature with selected regression algorithms over different land use land cover scenes. ISPRS Journal of Photogrammetry and Remote Sensing 96, 76-93. doi:10.1016/j.isprsjprs.2014.07.003

Gillies, R.R., Carlson, T.N., 1995. Thermal Remote-Sensing of Surface Soil-Water Content with Partial Vegetation Cover for Incorporation into Climate-Models. Journal of Applied Meteorology 34, 745-756. doi:10.1175/1520-0450(1995)034<0745:trsoss>2.0.co;2

Gutman, G., Ignatov, A., 1998. The derivation of the green vegetation fraction from NOAA/AVHRR data for use in numerical weather prediction models. International Journal of Remote Sensing 19, 1533-1543. doi:10.1080/014311698215333 
654

655

656

657

658

659

660

661

662

663

664

665

666

667

668

669

670

671

672

673

674

675

676

677

678

679

680

681

682

683

684

685

686

687

688

689

690

691

692

693

694

695

696

697

698

699

700

701

702

703

Hansen, J., Ruedy, R., Sato, M., Lo, K., 2010. Global surface temperature change. Rev. Geophys. 48. doi:10.1029/2010RG000345.

Inamdar, A.K., French, A., 2009. Disaggregation of GOES land surface temperatures using surface emissivity. Geophysical Research Letters 36, L02408. doi:10.1029/2008GL036544

Jarlan L, Khabba, S., Er-Raki, S., Page, M. Le, Hanich, L., Y. Fakir, O. Merlin, S. Mangiarotti, S. Gascoin, J. Ezzahar, M.H. Kharrou, B. Berjamy, A. Saaïdi, A. Boudhar, A. Benkaddour, N. Laftouhi, J. Abaoui, A. Tavernier, G. Boulet, V. Simonneaux, F. Driouech, M. El Adnani, A. El Fazziki, N. Amenzou, F. Raibi, A., R.E., 2015. Remote Sensing of Water Resources in the semi-arid Mediterranean areas: The Joint International Laboratory TREMA. International Journal of Remote Sensing, sous presse.

Karnieli, A., Agam, N., Pinker, R.T., Anderson, M., Imhoff, M.L., Gutman, G.G., Panov, N., Goldberg, A., 2010. Use of NDVI and land surface temperature for drought assessment: Merits and limitations. Journal of Climate 23, 618-633. doi:10.1175/2009JCLI2900.1

Khabba, S., Jarlan, L., Er-Raki, S., Page, M. Le, Ezzahar, J., Boulet, G., Simonneaux, V., Kharrou, M.H., Hanich, L., Chehbouni, G., 2013. The SudMed Program and the Joint International Laboratory TREMA: A Decade of Water Transfer Study in the Soil-PlantAtmosphere System over Irrigated Crops in Semi-Arid Area. Procedia Environmental Sciences 19, 524-33.

Kogan, F.N., 2001. Operational space technology for global vegetation assessment. Bulletin of the American Meteorological Society 82, 1949-1964. doi:10.1175/15200477(2001)082<1949:OSTFGV>2.3.CO;2

Kustas, W., Anderson, M., 2009. Advances in thermal infrared remote sensing for land surface modeling. Agricultural and Forest Meteorology 149, 2071-2081. doi:10.1016/j.agrformet.2009.05.016

Kustas, W.P., Norman, J.M., Anderson, M.C., French, A.N., 2003. Estimating subpixel surface temperatures and energy fluxes from the vegetation index-radiometric temperature relationship. Remote Sensing of Environment 85, 429-440. doi:10.1016/S0034-4257(03)00036-1

Liu, D., Zhu, X., 2012. An enhanced physical method for downscaling thermal infrared radiance. IEEE Geoscience and Remote Sensing Letters 9, 690-694. doi:10.1109/LGRS.2011.2178814

Liu, Y., Hiyama, T., Yamaguchi, Y., 2006. Scaling of land surface temperature using satellite data: A case examination on ASTER and MODIS products over a heterogeneous terrain area. Remote Sensing of Environment 105, 115-128. doi:10.1016/j.rse.2006.06.012

Merlin, O., 2013. An original interpretation of the wet edge of the surface temperature-albedo space to estimate crop evapotranspiration (SEB-1S), and its validation over an irrigated area in northwestern Mexico. Hydrology and Earth System Sciences 17, 3623-3637. doi:10.5194/hess-17-3623-2013

Merlin, O., Chehbouni, A.G., Kerr, Y.H., Njoku, E.G., Entekhabi, D., 2005. A combined modeling and multipectral/multiresolution remote sensing approach for disaggregation of surface soil moisture: Application to SMOS configuration. IEEE Transactions on Geoscience and Remote Sensing 43, 2036-2050. doi:10.1109/TGRS.2005.853192

Merlin, O., Duchemin, B., Hagolle, O., Jacob, F., Coudert, B., Chehbouni, G., Dedieu, G., Garatuza, J., Kerr, Y., 2010. Disaggregation of MODIS surface temperature over an agricultural area using a time series of Formosat-2 images. Remote Sensing of Environment 114, 2500-2512. doi:10.1016/j.rse.2010.05.025

Merlin, O., Jacob, F., Wigneron, J., Member, S., Walker, J., Chehbouni, G., 2012. Multidimensional Disaggregation of Land Surface and Microwave-L Bands 50, 18641880. 
Olivera-Guerra, L., Mattar, C., Merlin, O., Durán-Alarcón, C., Santamaría-Artigas, A., Fuster, R., 2017. An operational method for the disaggregation of land surface temperature to estimate actual evapotranspiration in the arid region of Chile. ISPRS Journal of Photogrammetry and Remote Sensing 128, 170-181. doi:10.1016/j.isprsjprs.2017.03.014

Olivera-Guerra, L., Merlin, O., Er-Raki, S., Khabba, S., Escorihuela, M.J., 2018. Estimating the water budget components of irrigated crops: Combining the FAO-56 dual crop coefficient with surface temperature and vegetation index data. Agricultural Water Management 208, 120-131. doi:10.1016/j.agwat.2018.06.014

Price, J.C., 1982. Estimation of Regional Scale Evapotranspiration Through Analysis of Satellite Thermal-Infrared Data. IEEE Transactions on Geoscience and Remote Sensing 20, 286-292. doi:10.1109/TGRS.1982.350445

Roerink, G.J., Su, Z., Menenti, M., 2000. S-SEBI: A simple remote sensing algorithm to estimate the surface energy balance. Physics and Chemistry of the Earth Part BHydrology Oceans and Atmosphere 25, 147-157. doi:doi.org/10.1016/S14641909(99)00128-8

Sandholt, I., Nielsen, C., Stisen, S., 2009. A Simple Downscaling Algorithm for Remotely Sensed Land Surface Temperature. American Geophysical Union, Spring Meeting 2009, abstract id. H24A-04.

Sandholt, I., Rasmussen, K., Andersen, J., 2002. A simple interpretation of the surface temperature/vegetation index space for assessment of surface moisture status. Remote Sensing of Environment 79, 213-224. doi:10.1016/S0034-4257(01)00274-7

Stefan, V.G., Merlin, O., Er-Raki, S., Escorihuela, M.J., Khabba, S., 2015. Consistency between In Situ, model-derived and high-resolution-image-based soil temperature endmembers: Towards a robust data-based model for multi-resolution monitoring of crop evapotranspiration. Remote Sensing 7, 10444-10479. doi:10.3390/rs70810444

Tardy, B., Rivalland, V., Huc, M., Hagolle, O., Marcq, S., Boulet, G., 2016. A Software Tool for Atmospheric Correction and Surface Temperature Estimation of Landsat Infrared Thermal Data 8, 696. doi:10.3390/rs8090696

Wan, Z., 1996. A generalized split-window algorithm for retrieving land-surface temperature from space. IEEE Transactions on Geoscience and Remote Sensing 34, 892-905. doi:10.1109/36.508406

Wan, Z., Zhang, Y., Zhang, Q., Li, Z. liang, 2002. Validation of the land-surface temperature products retrieved from terra moderate resolution imaging spectroradiometer data. Remote Sensing of Environment 38, 163-180. doi:10.1016/S0034-4257(02)00093-7

Williamson, H.D., 1988. Evaluation of middle and thermal infrared radiance in indices used to estimate GLAI. International Journal of Remote Sensing 9, 275-283. doi:10.1080/01431168808954851

Yang, H., Cong, Z., Liu, Z., Lei, Z., 2010. Estimating sub-pixel temperatures using the triangle algorithm. International Journal of Remote Sensing 31, 6047-6060. doi:10.1080/01431160903376373

Zhan, W., Chen, Y., Zhou, J., Li, J., Liu, W., 2011. Sharpening thermal imageries: A generalized theoretical framework from an assimilation perspective. IEEE Transactions on Geoscience and Remote Sensing 49, 773-789. doi:10.1109/TGRS.2010.2060342

Zhang, R., Tian, J., Su, H., Sun, X., Chen, S., Xia, J., 2008. Two improvements of an operational two-layer model for terrestrial surface heat flux retrieval. Sensors 8, 61656187. doi: $10.3390 / \mathrm{s} 8106165$ 